\title{
CHAPITRE 12
}

\section{PHYSIOLOGIE DE L'APPAREIL DE REPRODUCTION FEMELLE}

\section{GAMÉTOGENÈSE ET FOLLICULOGENÈSE}

La gamétogenèse correspond à la formation et à la maturation des gamètes ; c'est la spermatogenèse chez l'homme (voir chap. $13, \S 2$ ) et l'ovogenèse chez la femme.

La gamétogenèse a pour fonction principale de préparer les gamètes à une éventuelle fécondation, c'est-à-dire d'obtenir des cellules haploïdes à $n$ chromosomes qui donneront par leur union un zygote ou œuf à $2 \mathrm{n}$ chromosomes.

Chez la femme, la gamétogenèse est indissociable de la folliculogenèse : longue période de maturation allant du follicule primordial depuis le moment où il sort de la réserve ovarienne et évolue, en passant par diverses étapes qui aboutissent au follicule mûr pré-ovulatoire.

\subsection{ASPECTS MORPHOLOGIQUES DE LA FOLLICULOGENÈSE}

Morphologiquement, cette maturation s'accompagne de modifications ovocytaires et folliculaires séparées en cinq stades (fig. 12.1).

- Le follicule primordial mesure 15 à $25 \mu \mathrm{m}$; il est formé par l'association d'une cellule germinale, l'ovogonie ou ovocyte primordial (de premier ordre), qu'entoure une seule couche de cellules folliculaires dites de la granulosa et une fine membrane lamellaire, la membrane de Slavjansky.

- Le follicule primaire a une taille plus importante $(50 \mu \mathrm{m}) \mathrm{du}$ fait de la forte augmentation volumétrique du noyau de l'ovocyte situé au centre du follicule. Une seule couche de cellules folliculaires entoure le gamète.

- Le follicule secondaire, dit encore follicule plein, poursuit sa croissance, mesure de 50 à $500 \mu \mathrm{m}$, avec un gros ovocyte central qu'entourent quatre à cinq couches de cellules de la granulosa. La multiplication de ces dernières est très active, au point que, à ce stade, on peut bien distinguer une couche péri-ovocytaire, la corona radiata, séparée du gamète par la membrane pellucide, dite encore membrane vitelline. 


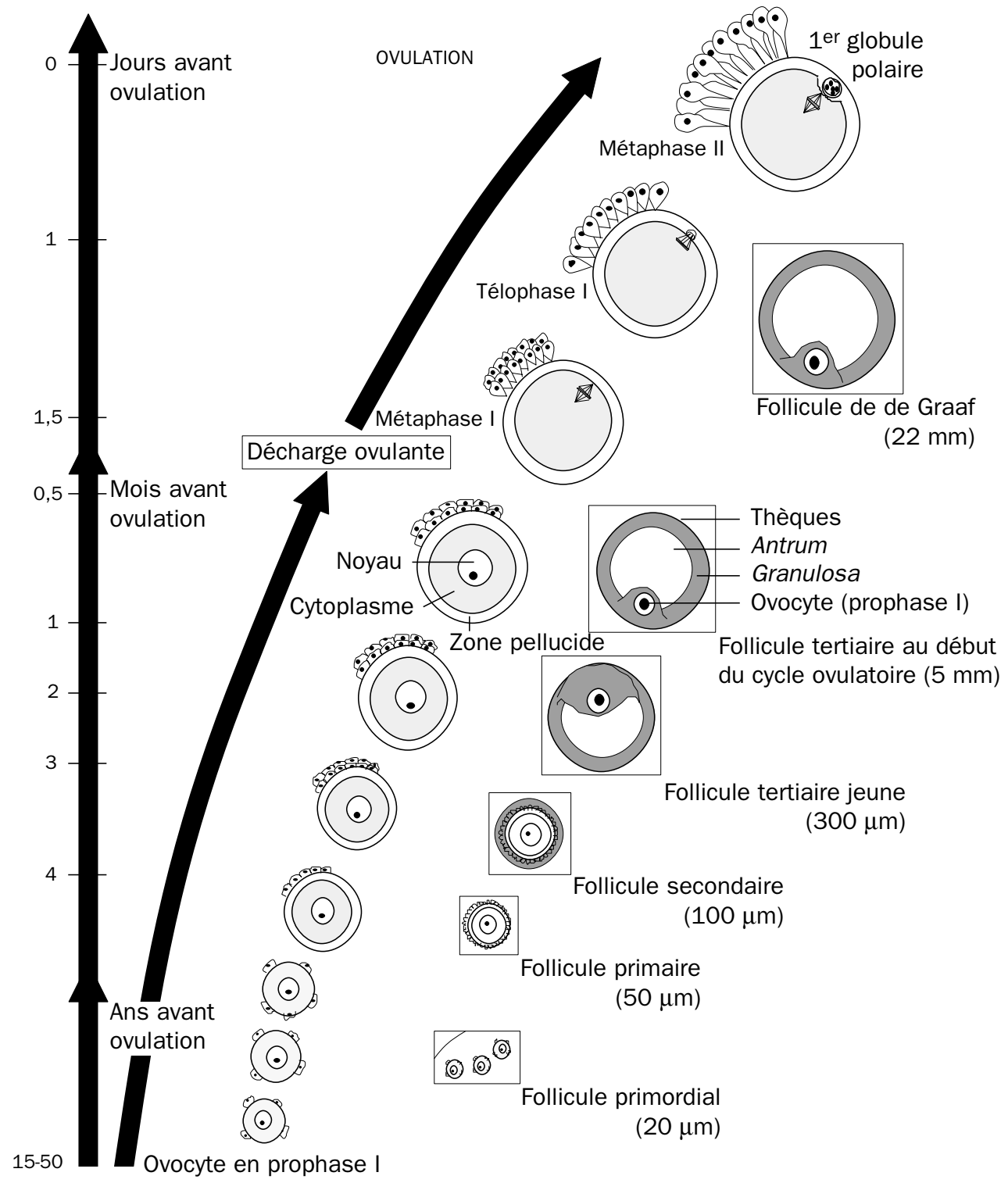

Figure 12.1 - L'ovogenèse chez les Mammifères (d'après Testart, 1982)

- Le follicule antral (cavitaire ou tertiaire) de $500 \mu \mathrm{m}$ à 10-15 mm de diamètre, avec un ovocyte de l'ordre de $100 \mu \mathrm{m}$ disposé de façon excentrique et six à dix couches de cellules de la granulosa creusées de l'antrum du fait de la production de liquor folliculi. A l'extérieur de la membrane de Slavjansky se sont différenciées deux thèques :

- la thèque externe, principalement conjonctive et fibreuse,

- la thèque interne, véritable glande endocrine avec ses cordons cellulaires richement vascularisés. 
- Le follicule pré-ovulatoire, ou follicule de de Graaf, terme de cette évolution, est encore beaucoup plus gros, puisque sa taille peut dépasser 15-30 $\mathrm{mm}$ de diamètre. C'est le follicule mûr avec ses structures histologiquement bien différenciées.

\subsection{ASPECTS DYNAMIQUES DE LA FOLLICULOGENÈSE}

D'un point de vue dynamique, dans l'espèce humaine, la production ovocytaire s'étale sur une période relativement brève entre 12 ans, âge habituel de la puberté, et 50 ans, âge de la ménopause. Cependant l'évolution de la lignée germinale commence très tôt, dès la période fotale. En effet, entre le $2^{\mathrm{e}}$ et le $7^{\mathrm{e}}$ mois de la vie intra-utérine, la corticalité de l'ovaire fœetal est le siège d'une active multiplication des ovogonies (6 à 7 millions à 5 mois de gestation) qui atteignent près du terme le nombre de plusieurs millions ; un capital unique et définitif qui constitue le pool de réserve primordial. Toutes ces ovogonies à $2 \mathrm{n}$ chromosomes, dès leur différenciation, ont amorcé une méiose qui s'est bloquée en prophase au stade diplotène.

A la naissance, les ovaires ne possèdent plus que 2 millions d'ovocytes primaires, prouvant ainsi qu'un assez grand nombre d'entre eux a déjà involué. Lors de l'enfance, 90\% des follicules primordiaux, ainsi que leurs ovocytes, vont évoluer au maximum jusqu'au stade antral et ensuite dégénérer. A la puberté, il ne reste plus dans l'ovaire que 100 à 400000 follicules primordiaux dont le plus grand nombre va encore s'atrésier à divers stades de l'évolution, pour ne laisser, à 45 ans, qu'un stock de réserve de l'ordre de 1500 éléments.

Pendant le cycle, en début de phase folliculaire, dix à quarante follicules sortent de la réserve, seule une cohorte de cinq à dix follicules tertiaires sont recrutés, un seul, dit follicule dominant ${ }^{1}$, va ovuler, terminer la division réductionnelle de la méiose, émettre le premier globule polaire et engendrer l'ovocyte de deuxième ordre, haploïde, en attente d'une éventuelle fécondation. Ainsi, seulement 500 ovocytes ont le privilège de terminer leur ultime évolution pendant les 40 ans que dure la vie de reproduction. Seuls ces 500 ovocytes auront la possibilité de décondenser le noyau spermatique lors de la fécondation. Si l'on considère l'importance du stock initial et le résultat final, la disparition de la plupart des cellules germinales (99\% des follicules qui entrent en croissance dégénèrent au cours de leur développement) apparaît comme un gaspillage phénoménal. On sait qu'il faut 25 jours pour passer du follicule secondaire au follicule antral, que 60 jours sont nécessaires à celui-ci pour mûrir et devenir "pré-ovulatoire". Ainsi, le follicule qui ovule à un cycle donné a commencé son ultime évolution au moins trois cycles auparavant (fig. 12.2). Ceci laisse escompter que les résultats d'une thérapeutique sur le follicule seront complets seulement 3 mois après son administration.

1 La "dominance" pourrait résulter, selon Dizerega et coll. (1980), de la sécrétion par le follicule dominant d'une protéine appelée FRP (follicular regulary protein), qui jusqu'à présent n'a pas encore été identifiée. 


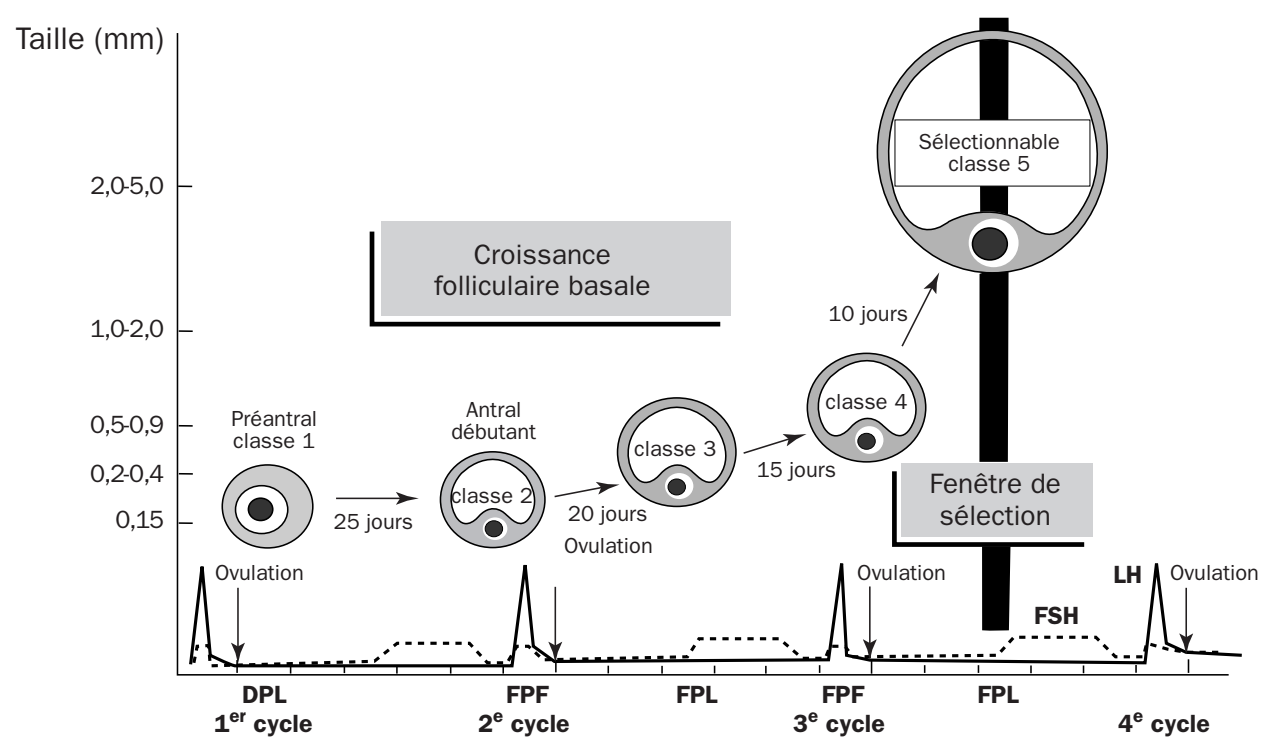

Figure 12.2 - Chronologie du développement folliculaire de la cohorte d'où sera issu le follicule ovulatoire (d'après Gougeon, 1996)

DPL : début de phase lutéale ; FPF : fin de phase folliculaire ; FPL : fin de phase lutéale ; FSH : follicle stimulating hormone ; $\mathrm{LH}$ : luteinizing hormone.

On peut définir deux grandes phases dans la croissance du follicule ovarien :

- une phase de croissance "basale" des cellules de la granulosa, qui va du stade follicule primordial au stade follicule de $5 \mathrm{~mm}$ chez la femme. Cette phase est indépendante de l'action des gonadotrophines, elle est essentiellement sous la dépendance de facteurs de croissance à action paracrine. D'après des expériences "in vitro", ces facteurs appartiennent à la famille de l'EGF (epidermal growth factor), des IGF (insulin-like growth factor), du TGF $\beta$ (transforming growth factor) et du FGF (fibroblast growth factor).

L'absence d'hormonosensibilité de la phase initiale de la folliculogenèse implique qu'elle est difficile sinon impossible à manipuler en clinique humaine par opposition à l'évolution terminale de la cohorte folliculaire recrutée en début de cycle, directement liée aux taux de FSH en phase menstruelle et en tout début de première phase.

- une phase de croissance "dépendante des gonadotrophines", qui va de la fin de la croissance "basale" jusqu'à l'ovulation. La folliculogenèse ovarienne est donc caractérisée par des processus d'intense prolifération puis de différenciation (stéroïdogenèse) des cellules de la granulosa dans les follicules en croissance, mais aussi d'apoptose dans les follicules atrétiques. Des expériences de transgenèse chez la souris ont permis de confirmer le fonctionnement des gènes impliqués dans la régulation endocrine et paracrine de ces phénomènes (Monget et coll., 1999). 
La sélection folliculaire correspondant à l'émergence du follicule ovulatoire est en relation avec le rétro-contrôle négatif de l'inhibine et l'œstradiol qui détermine, d'une part, l'involution des follicules hormonosensibles et, d'autre part, l'évolution terminale du follicule dominant qui deviendra ovulatoire. Dès le stade pré-ovulatoire, le follicule dominant (parfois plusieurs dans les grossesses multiples) est détectable par exploration cœlioscopique ou par échographie pelvienne. Il mesure de 15 à $20 \mathrm{~mm}$, bombe en général au niveau de la corticalité ovarienne et s'apprête à subir les profondes modifications contemporaines de la ponte ovulaire.

La maturation de l'ovocyte est souvent associée à la méiose. Cependant elle recouvre également des phénomènes cytoplasmiques moins bien connus mais d'une grande importance. Cette maturation, très complexe, va permettre à l'ovule d'acquérir sa capacité d'assumer la fécondation et de préparer le développement embryonnaire. Trois aspects (noyau, cytoplasme et environnement somatique) vont évoluer pour déterminer cette capacité :

1. au niveau du noyau, la reprise de la méiose correspondrait à un passage entre le stade $\mathrm{G} 2$ et le stade $\mathrm{M}$ du cycle cellulaire. Cette reprise repose sur l'activation du MPF (M-phase promoting factor), hétérodimère composé de la protéine $\mathrm{P} 34 \mathrm{Cdc} 2$ et d'une cycline B. L'ovocyte restera alors en métaphase II jusqu'à l'entrée du spermatozoïde. Le blocage à ce stade est dû à un facteur cytostatique dont la nature n'est pas encore établie.

2. au niveau du cytoplasme, c'est la concentration des granules corticaux aux abords de la membrane plasmique. Il s'agit de petites vésicules sphériques de 200 à $600 \mathrm{~nm}$ de diamètre ; la libération de leur contenu enzymatique dans l'espace vitellin lors de la fécondation provoquera des modifications de la structure de la zone pellucide, empêchant la pénétration de spermatozoïdes surnuméraires.

3. au niveau de l'environnement, un des phénomènes importants est l'expansion du cumulus proliger. Cette expansion s'installe du fait de l'effet positif de la FSH du liquor folliculi dont l'action serait modulée par la LH. Il en résulte une production par les cellules du cumulus d'une matrice viscoélastique riche en acide hyaluronique. Ceci entraine, d'une part, la séparation du complexe cumulo-ovocytaire du reste des cellules de la granulosa et, d'autre part, l'augmentation du contenu hydrique de l'antrum.

Le liquor folliculi et les cellules de la granulosa se chargent en activateurs du plasminogène, ce qui entraîne une ascension des taux de plasmine. L'albuginée (enveloppe ovarienne) sécrète des enzymes protéolytiques, en particulier des collagénases. Les cellules de la granulosa produisent des substances inductrices de l'angiogenèse, vectrices de macrophages, mastocytes, polynucléaires et des prostaglandines qui vont intervenir dans le processus de rupture folliculaire. 
L'appareil neuromusculaire périfolliculaire, également sollicité, participe à l'ovulation par le biais probable de catécholamines que régulent les gonadotrophines, et par celui de facteurs locaux que libèrent les cellules de la granulosa.

La déhiscence folliculaire résulte de l'harmonieuse coordination de tous ces phénomènes. Elle implique également la participation de prostaglandines et de récepteurs adrénergiques capables de modifier la microcirculation de l'apex folliculaire et d'entraîner, à ce niveau, la dégénérescence des cellules épithéliales déterminant la libération d'hydrolases lysosomiales qui achèvent la destruction de la paroi folliculaire.

\section{L'ATRÉSIE FOLLICULAIRE}

L'atrésie des $99 \%$ de follicules qui entrent en croissance dans l'ovaire est moins bien connue dans les follicules pré-antraux que dans les follicules à antrum.

Elle est caractérisée par l'arrêt de la prolifération et la mort par apoptose ${ }^{2}$. L'induction de l'apoptose est suivie par la libération d'éléments mitochondriaux, l'activation de protéases et d'endonucléases, conçue comme une étape finale de la dégradation de l'ADN. L'ensemble de ces phénomènes constitue une mort cellulaire programmée. Il y a en fait deux formes d'atrésie folliculaire, l'une a l'ovocyte pour cible et touche les follicules pré-antraux, particulièrement à la fin de la vie fotale et pendant la période prépubertaire, l'autre a pour cibles les cellules de la granulosa et touche uniquement les follicules à antrum.

Le déterminisme de l'atrésie folliculaire, qui aboutit à la sélection d'un lot limité de follicules ovulatoires (et en général un seul hors de chaque cycle ovarien), est complexe. Il semble que n'importe quel follicule qui entre en développement terminal hors d'une vague folliculaire ait les potentialités de se développer jusqu'au stade préovulatoire. Chaque follicule est caractérisé par un équilibre local entre des facteurs paracrines stimulants (œstradiol, IGF, activine...) et inhibiteurs (androgènes, IGFBP ou IGF binding proteins, follistatine...). Seul le follicule le mieux adapté continuerait son développement (évolution opportuniste plutôt que prédéterministe). Les autres, sous l'effet d'une augmentation de la synthèse de facteurs inhibiteurs et la perte de synthèse de facteurs stimulants, rentreraient en atrésie : activation de Fas et du récepteur du TNF $\alpha$ (tumor necrosing factor), déséquilibre en faveur des facteurs proapoptotiques (Bcl-2), activation de p53 et des caspases (Monniaux et coll., 1999).

2 Une apoptose limitée $(<2 \%$ des cellules de la granulosa) se manifeste toutefois dans la quasi-totalité des follicules en croissance, et même dans certains follicules pré-ovulatoires. 


\section{L'OVULATION}

L'ovulation proprement dite correspond à la rupture folliculaire. C'est un phénomène bref en réponse au signal gonadotrope ovulatoire, qui conduit à la libération de l'ovocyte mûr dans les voies génitales ${ }^{3}$. Elle est cliniquement précédée par une tension du bas-ventre parallèle à la mise en pression du liquor folliculi.

L'éclatement folliculaire, quant à lui, n'est pas perçu ; en revanche, l'épanchement intrapéritonéal conséquent détermine habituellement une réaction pelvienne douloureuse due à l'irritation du péritoine adjacent. D'ordinaire, l'épanchement est modéré, de 50 à $100 \mathrm{ml}$, déterminant un syndrome du 14e jour que connaissent bien les femmes fonctionnelles. Parfois, en particulier dans les syndromes d'hyperstimulation ovarienne, apparaissent de véritables hémorragies avec douleur "exquise", anémie et signes péritonéaux si préoccupants qu'il convient d'intervenir pour assurer une hémostase correcte du follicule rompu.

Au moment de son expulsion, l'ovocyte, jusqu'alors bloqué en prophase de première division méiotique par l'effet de l'OMI (ovocyte maturation inhibitor), se trouve libéré de cet effet (fig. 12.3), et termine rapidement sa multiplication qui aboutit à deux cellules filles très inégales en valeur et en volume : l'ovocyte secondaire, ou de deuxième ordre, de $100 \mu$ environ, conservant la presque totalité du cytoplasme de la cellule mère et le premier globule polaire nettement plus petit, repoussé à la périphérie ovocytaire sous la membrane pellucide dans l'espace périvitallin. La deuxième division méiotique commence aussitôt et restera à son tour bloquée en métaphase jusqu'à une éventuelle fécondation. L'AMPc semble également jouer un rôle important dans le blocage et la reprise de la méiose dans de nombreuses espèces.

Ainsi, entouré de la membrane pellucide et des cellules du cumulus oophorus ou corona radiata, le gamète femelle constitue une masse visqueuse de plusieurs millimètres cubes que recueille le pavillon tubaire dont les franges embrassent littéralement l'ovaire : c'est le "baiser de la trompe", un phénomène actif que facilite la turgescence des franges du pavillon.

Le transit tubaire, en revanche, est un phénomène passif que favorise le courant des sécrétions tubaires allant du pavillon vers l'utérus. Les contractions tubaires et l'activité ciliaire de la muqueuse endoluminale jouent également un rôle. Le trajet dure habituellement 4 jours et, en l'absence de fécondation, l'ovule dégénère et s'évacue dans la cavité utérine. Dans le cas contraire, lorsque, dans le tiers externe de la trompe, la fécondation se produit, on assiste à la fin de la deuxième mitose réductionnelle, à

3 Deux phénomènes sont importants pour la datation de l'ovulation : la température de base (effet de la progestérone) et la glaire cervicale (effet des œstrogènes). Par ailleurs, on trouve actuellement dans le commerce des tests à lecture colorimétrique qui permettent de détecter (à domicile), à l'aide d'anticorps monoclonaux, la décharge ovulante de LH (donc 24 à 46 h avant l'ovulation). 
l'émission du deuxième globule polaire, à la transformation de l'œuf fécondé en morula puis en blastocyste qui va se fixer dans la cavité utérine vers le $20^{\mathrm{e}}$ jour du cycle.

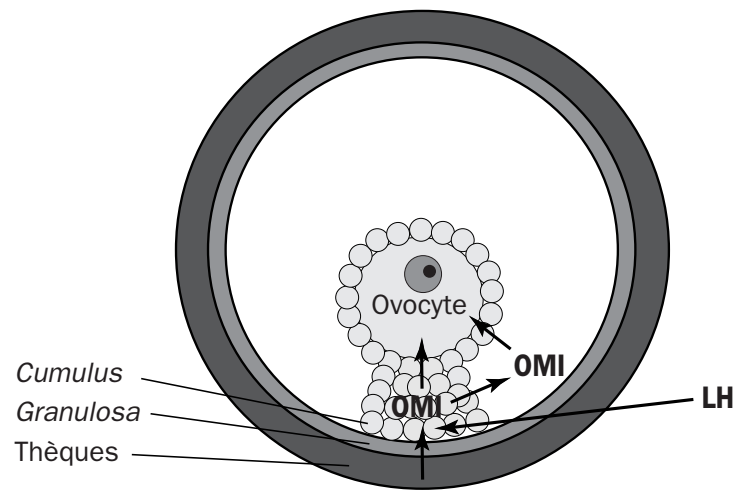

Figure 12.3 - Schéma hypothétique du blocage méiotique intrafolliculaire (d'après Mermillod et Marchal, 1999)

Un signal inhibiteur serait originaire de la thèque interne et transmis à la granulosa. Celle-ci activerait ce signal et le transmettrait à l'ovocyte via les jonctions perméables ou le fluide folliculaire (OMI). Lors de la décharge gonadotrope ovulante (LH), ce signal inhibiteur ne serait plus transmis par la granulosa.

Pathologiquement, du fait d'une sténose tubaire ou d'une endométriose, l'œuf peut se fixer dans la trompe et réaliser le tableau d'une grossesse extra-utérine (GEU). L'évolution de cette grossesse ectopique s'accompagne de mise en tension de la trompe, de douleurs et d'hémorragie intrapéritonéale par rupture de la paroi tubaire, ce qui nécessite une intervention médico-chirurgicale d'urgence.

Dès l'ovulation, le follicule rompu, vidé de son contenu, se transforme en un corps jaune à fonction endocrine : la membrane de Slavjansky se dissocie, ceci permet aux vaisseaux d'envahir la granulosa dont les cellules se lutéinisent, c'est-à-dire se vacuolisent et se chargent de lipides tout en assurant la sécrétion des œstrogestatifs ovariens de la deuxième phase ou cycle. La thèque externe s'épaissit pendant que les cellules de la thèque interne s'hypertrophient et migrent de façon centripète en passant par les intervalles que laisse la membrane de Slavjansky.

La survie du corps jaune hors fécondation correspond à une activité fonctionnelle d'environ 10 à 12 jours. Il involue ensuite en corpus albicans ou corps blanc, s'atrésie et laisse sa cicatrice sous forme d'une rétraction fibreuse plus ou moins étoilée au niveau de la corticalité ovarienne. Lorsqu'il y a fécondation, le corps jaune devient gestatif (ou gravidique), persistant jusqu'aux environs du $3^{\mathrm{e}}$ mois de grossesse, date approximative du relais placentaire.

L'ovulation est dite spontanée lorsqu'elle est cyclique ; c'est le cas chez la femme où elle survient tous les 28 jours, la rate ou la souris (tous les 4 ou 5 jours), le cobaye (tous les 15 jours) ou la vache (tous les 21 jours), la plupart des animaux sauvages (une fois par an) ou la chienne (deux fois par an). 
L'ovulation est dite provoquée, par exemple chez la lapine, le furet ou la chatte. Dans ce cas, ce sont des réflexes tacto-hypothalamo-hypophysaires contemporains du coït qui déclenchent la ponte.

D'autres espèces peuvent avoir une ovulation postcoïtale différée, telle la chauvesouris qui ovule 3 mois après la copulation.

\section{LES CYBERNINES OVARIENNES}

Les cybernines ovariennes sont des substances polypeptidiques produites par l'ovaire ; elles interviennent à toutes les étapes de la folliculogenèse et de l'ovulation.

\subsection{L'INHIBITEUR DE LA MATURATION OVOCYTAIRE (OMI)}

L'inhibiteur de la maturation ovocytaire serait un polypeptide dont la taille est encore imprécise, sécrété par les cellules folliculaires de la granulosa. Plusieurs candidats à activité OMI ont été proposés : le TGF $\beta$, l'AMH (antimullerian hormone), l'activine, l'inhibine (voir plus loin), ou encore une protéine de $60 \mathrm{kDa}$. L'OMI, qui pourrait être d'origine thécale, est libéré dans le liquor folliculi et inhibe la première méiose de maturation ovocytaire bloquée en prophase (voir fig. 12.2). Plus le follicule est petit, plus la concentration de l'OMI est importante. C'est la dissociation des cellules du cumulus proliger et la désolidarisation de l'ovocyte lors de la ponte qui déterminent la reprise et l'accomplissement de la première méiose de maturation.

\subsection{L'INHIBITEUR DE LA FIXATION DE FSH (FSH-BI)}

C'est une cybernine de 700 daltons qui empêche la fixation de FSH sur ses récepteurs. De ce fait, la FSH-BI va, d'une part, isoler le follicule dominant dès le $5^{\mathrm{e}}$ jour du cycle et, d'autre part, bloquer l'évolution éventuelle d'autres follicules hormonodépendants. Par ailleurs, comme la maturation des cellules de la granulosa est liée à la FSH et que l'aromatisation du noyau $\mathrm{A}$ des androgènes de la thèque aboutit au $17 \beta$-œstradiol, on peut dire que la FSH-BI entraîne une accumulation d'androgènes et une carence œstrogénique. De même, comme c'est la FSH qui induit la synthèse des récepteurs pour la LH et la sécrétion progestative, on peut dire que la FSH-BI voue le follicule à l'involution et à l'atrésie.

\subsection{L'INHIBITEUR DE LA LUTÉINISATION (LI)}

La transformation du follicule rompu en corps jaune se fait en quelques heures mais, si l'on isole des cellules folliculaires en culture avant l'ovulation, elles se lutéinisent spontanément. D'où l'idée vérifiée que l'ovocyte puisse être à l'origine d'une substance 
inhibant la lutéinisation spontanée. Il s'agit, en fait, de deux polypeptides de 3500 et 10000 daltons diminuant la synthèse d'AMPc et la sécrétion progestative.

\subsection{LES CYBERNINES INTERVENANT DANS LA RÉGULATION HYPOTHALAMO-HYPOPHYSO-GONADIQUE}

Entre l'ovaire et le système nerveux central s'établit un rétro-contrôle permanent auquel participent plusieurs cybernines ovariennes.

\subsubsection{L'inhibine}

L'inhibine a été isolée et caractérisée en 1985. C'est une hormone glycoprotéique produite par les cellules de la granulosa, la thèque interne, les cellules lutéales et le placenta. Son rôle physiologique essentiel est d'inhiber la sécrétion de la FSH hypophysaire.

Elle existe sous deux formes, $\mathrm{A}$ et $\mathrm{B}$, qui possèdent la même sous-unité $\alpha$ mais avec une sous-unité associée $\beta \mathrm{A}$ ou $\beta \mathrm{B}$ (de structure voisine de la TGF $\beta$ ).

En phase folliculaire, sous l'effet de la FSH, la concentration de l'inhibine B dans le plasma crôt avec la taille du follicule (et son taux dans le liquor folliculi va en augmentant) puis, après un bref pic post-ovulatoire, décroît en phase lutéale. Ce profil est l'inverse de celui de l'inhibine A qui s'élève progressivement en phase folliculaire tardive, suit le pic de LH, puis remonte à nouveau en phase lutéale. La régulation de la FSH au cours du cycle menstruel est cependant davantage liée à l'œstradiol qui s'élève bien avant la diminution de l'inhibine.

A contrario, lors de la lutéolyse, la diminution de l'activité sécrétoire du corps jaune entraîne une augmentation relative de la FSH périmenstruelle, ce qui va susciter le recrutement folliculaire du cycle suivant.

L'action de l'inhibine serait spécifique et s'exercerait sur un site hypophysaire différent de celui de la GnRH, car l'œstradiol, qui a des effets similaires, agit non seulement sur l'hypophyse mais aussi sur la LH hypothalamique, action non-observée pour l'inhibine.

\subsubsection{L'activine et la follistatine}

Au cours des étapes de la purification de l'inhibine, on a découvert deux autres protéines synthétisées par l'ovaire : l'activine, dimère des sous-unités $\beta$ de l'inhibine, activatrice de la sécrétion de FSH et la follistatine, polypeptide glycosylé, qui est fortement liée à l'activine.

L'activine a surtout des activités autocrines et paracrines au niveau de l'ovaire. La régulation de la FSH par l'activine s'exerce directement au niveau des cellules gonadotropes hypophysaires, l'activine comme la follistatine étant également sécrétées par l'hypophyse. 


\subsubsection{Les gonadocrines}

De même, les gonadocrines, polypeptides de 3500 daltons isolés dans le liquor folliculi, seraient capables de se fixer sur les récepteurs GnRH pour les stimuler, tant au niveau central qu'au niveau ovarien.

\section{BIOCHIMIE DES HORMONES SEXUELLES CHEZ LA FEMELLE}

L'ovaire peut être divisé en deux compartiments capables de produire des hormones sexuelles :

- le compartiment interstitiel, fait des cellules du stroma ovarien et du hile, qui produisent, sous l'effet de la LH, des androgènes (androstène-dione et DHEA) ${ }^{4}$;

- le compartiment folliculaire, où l'unité fonctionnelle thèque interne-granulosa produit dans le liquor folliculi et dans le sang, de façon cyclique, le $17 \beta$-œstradiol et la progestérone 5 .

Les cellules endocrines de l'ovaire contiennent, à leur surface, des récepteurs aux LDL. Ces récepteurs permettent de lier les $\operatorname{LDL}^{6}$ et de les internaliser, ce qui va permettre un apport de cholestérol dont les LDL sont riches. C'est à partir de ce cholestérol et sous l'influence de la LH que la synthèse des hormones stéroïdes est possible (fig. 12.4).

Figure 12.4 - Schéma général des voies de synthèse des stéroïdes ovariens

A : $\Delta 4$-androstène-dione

DHEA : déhydro-épiandrostérone

E1 : œstrone

E2 : œstradiol

$P$ : progestérone

Pgn : prégnénolone

$T$ : testostérone.

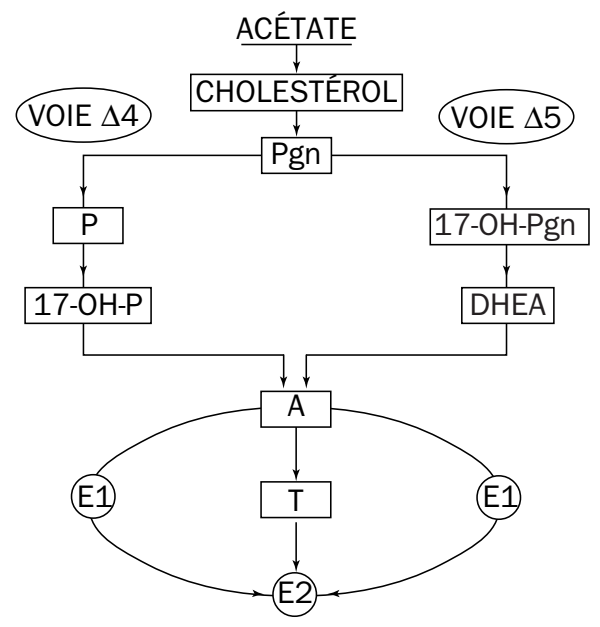

4 Chez la femelle hypophysectomisée, qui ne sécrète donc pas de FSH, l'injection de LH stimule essentiellement, dans l'ovaire, l'élaboration de ces androgènes.

5 L'ovaire élabore également de la relaxine, substance polypeptidique intervenant peut-être au moment de l'accouchement.

6 LDL : low density lipoproteins ou lipoprotéines de basse densité (20 à 25\% seulement de protéines); elles représentent les principaux transporteurs du cholestérol dans le sang. 


\subsection{LES HORMONES GESTROGÈNES}

\subsubsection{Origine et nature des hormones aestrogènes (fig. 12.5)}

Ce sont :

- L'œstrone ou folliculine. Elle est d'origine essentiellement placentaire. Ce n'est pas la véritable hormone ovarienne, bien que l'ovaire en sécrète une faible quantité $(\approx 30 \mathrm{ng} / \mathrm{ml}$ de liquor folliculi) .

- L'ostradiol ou dihydrofolliculine (E2), qui est le principal œstrogène ovarien. Il possède un $\mathrm{OH}$ en $17 \beta$.

- L'ostriol (non-détecté dans le sang), détecté dans le liquor folliculi uniquement pendant la phase lutéinique du cycle ( $24 \mu \mathrm{g}$ pour $10 \mathrm{~g}$ de liquor folliculi).

Les œstrogènes ne sont pas libres dans le sang mais liés à des protéines plasmatiques ( $\beta$-lipoprotéines). Cette liaison est faible et transitoire.

Si la source principale de ces hormones est le follicule cavitaire, elles sont également sécrétées par les cellules interstitielles de l'ovaire, le corps jaune, le placenta, le testicule et le cortex surrénal pathologique. Elles provoquent le rut chez la femelle impubère et chez la femelle castrée.

La thèque interne élabore à partir du cholestérol des stéroïdes androgènes (en C19), androstène-dione et testostérone, qui vont constituer des précurseurs de la biosynthèse des œstrogènes. Cette thèque interne possède des récepteurs à la $\mathrm{LH}$ et la castration ou la ménopause, en provoquant l'augmentation de la LH, entraîneront une stimulation de cette sécrétion d'androgènes ovariens.

Les cellules de la granulosa sont dépourvues de 17-hydroxylase et de desmolase, mais elles possèdent l'équipement enzymatique nécessaire à l'aromatisation des androgènes de la thèque interne, qu'elles convertissent en œstrogènes sous l'action de la FSH. Elles possèdent également des récepteurs à l'œstradiol, d'où une action "mitogénique" entrânant une multiplication cellulaire 7.

Au cours de la phase folliculaire, les cellules de la thèque interne, stimulées par la LH, produisent une quantité accrue d'androgènes que les cellules de la granulosa, stimulées par la FSH, transforment en œstrogènes. La thèque interne est toutefois capable de sécréter directement des œstrogènes. La granulosa a une capacité de synthèse à peu près constante d'œstradiol, alors qu'avec la croissance du follicule la thèque acquiert une autonomie de production des œstrogènes avec potentialisation de ses sécrétions : c'est une coopération cellulaire.

7 Cet effet est indépendant de l'action de la FSH mais, en multipliant les cellules folliculaires, il potentialise l'action de la FSH sur ses récepteurs. Les actions de l'œstradiol et de la FSH sont donc synergiques. 


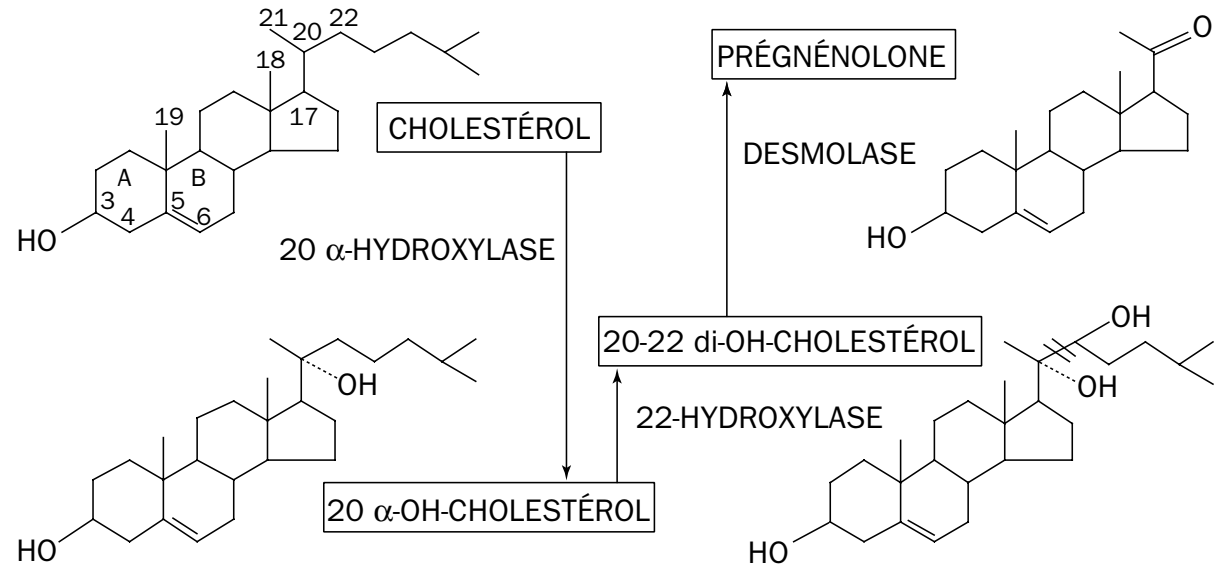

Première étape : synthèse de la prégnénolone à partir du cholestérol

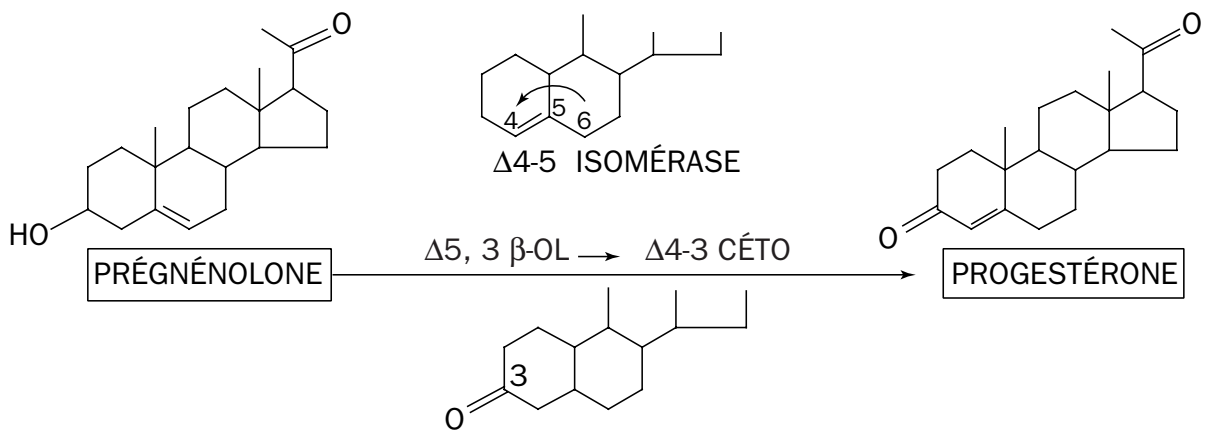

$3 \beta$-OL-DÉSHYDROGÉNASE

Deuxième étape : voie $\Delta 4$, de la prégnénolone à la progestérone<smiles>CC12CCC(=O)C=C1CCC1C2CCC2(C)C(O)CCC12</smiles>

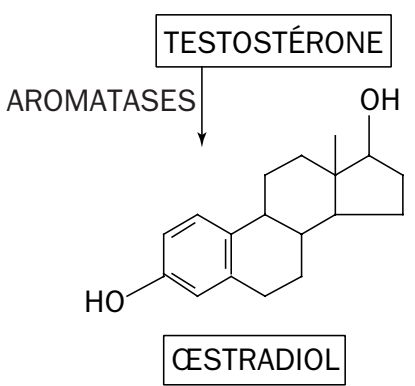

\section{7 -DÉSHYDROGÉNASE}

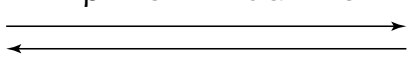

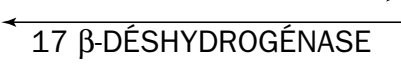<smiles>CC12CCC3C(CCC4=CC(=O)CCC43C)C1CCC2=O</smiles>

$\triangle 4$-ANDROSTÈNE-DIONE<smiles>CC12CCC3c4ccc(O)cc4CCC3C1CCC2=O</smiles>

CESTRONE

Dernière étape : synthèse des œstrogènes à partir des androgènes

Figure 12.5 - Biosynthèse des hormones sexuelles femelles 


\subsubsection{Catabolisme des hormones aestrogènes}

Au niveau du foie, $20 \%$ des œstrogènes seront excrétés dans l'urine sous forme conjuguée (sulfo- ou glucurono-conjuguée). On y trouve surtout de l'œstriol (trihydrofolliculine) et de l'œstrone dans un rapport voisin de 1 (l'œstriol est un catabolite de l'œstrone).

\subsubsection{Action physiologique des aestrogènes}

Les œstrogènes ont une action sur le tractus génital et des effets métaboliques.

Dans le cadre de l'action sur la sphère génitale, on distingue :

- la restauration de l'endomètre utérin (voir § 6.2);

- l'augmentation de la contractibilité myométriale et l'accroissement de la sensibilité à l'ocytocine ;

- l'action sur la filance de la glaire cervicale (voir § 6.2);

- l'effet majorant sur le péristaltisme tubaire, ce qui peut, en cas d'excès, entraîner dans l'utérus des blastocystes immatures incapables de nidation ;

- l'effet prolifératif sur la muqueuse vaginale ;

- l'action sur la croissance des canaux galactophores ;

- l'action sur la croissance folliculaire, en sachant toutefois qu'à forte dose, prolongée, les œstrogènes entraînent une atrophie ovarienne par action directe et rétroaction hypophysaire.

Dans le cadre des actions métaboliques, les œstrogènes

- favorisent les rétentions hydrosodées ;

- stimulent l'activité des ostéoblastes, d'où leur utilité dans le traitement préventif et curatif de l'ostéoporose ;

- déterminent une augmentation du bon cholestérol (le HDL ou high density lipoproteins), ce qui justifie leur utilité dans le traitement préventif des artériopathies de surcharge.

Enfin, les œstrogènes sont hypothermisants : la température corporelle basale reste inférieure à $37^{\circ} \mathrm{C}$ pendant la phase folliculaire.

L'œstradiol stimule la synthèse et la libération de prolactine, ce qui explique l'aggravation des adénomes hypophysaires à prolactine lors des contraceptions orales.

\section{Estrogènes et physiologie artérielle}

L'effet cardio-protecteur des œstrogènes a été très étudié mais les mécanismes par lesquels les œstrogènes protègent de l'athérosclérose n'est pas encore très clair. Les œstrogènes augmentent la biodisponibilité de $\mathrm{NO}$ au niveau des artères chez la lapine castrée, le rat, le cochon d'Inde, le cochon. Cette action ne résulte pas d'une augmentation de la production de NO, mais plutôt d'une moindre dégradation de NO, secondaire à une diminution de la génération d'anions superoxydes par l'endothélium. 
Les hormones œstrogènes agissent sans doute également sur les cellules monocytaires, lymphocytes et monocytes/macrophages, retrouvées dans la paroi artérielle saine ou pathologique.

\subsubsection{Dosages biologiques et chimiques des aestrogènes}

Le dosage biologique repose sur certaines des actions caractéristiques des œstrogènes :

- déclenchement de l'œstrus et réactions vaginales qui l'accompagnent ; il est testé sur les Rongeurs (test d'Allen et Doisy) et l'on a défini une unité "souris" et une unité "rat" telles que, par exemple, $1 \mathrm{mg}$ d'œstradiol est égal à 10000 unités "souris";

- test de la pigmentation des plumes du chapon; la pigmentation noire chez la race Leghorn dorée est liée au génotype neutre, donc mâle ; l'injection d'œstrogène chez le chapon déplumé redonnera la plume qui repousse brun clair ;

- augmentation du poids utérin.

Ces dosages, de même que les dosages chimiques, n'ont plus qu'une valeur historique et ont été remplacés par le dosage radioimmunologique de l'œstradiol.

- Au cours du cycle œstrien :

- en phase folliculaire : 66 à $120 \mathrm{pmol} / 1=18$ à $40 \mathrm{ng} / 1$;

- en phase pré-ovulatoire : 173 à $890 \mathrm{pmol} / 1=45$ à $250 \mathrm{ng} / 1$;

- en phase post-ovulatoire : 96 à 545 pmol/1 = 25 à $150 \mathrm{ng} / 1$.

- Au cours de la grossesse :

- à la $12^{\mathrm{e}}$ semaine : $10600 \mathrm{pmol} / 1$;

- à la 24e semaine : $93000 \mathrm{pmol} / 1$;

- à la $37 \mathrm{e}$ semaine : $129000 \mathrm{pmol} / 1$.

- Au cours de la ménopause : 50 à $80 \mathrm{pmol} / 1$.

\subsubsection{Mode d'action des oestrogènes}

Le récepteur aux œstrogènes (R-E $\alpha)$ a été mis en évidence dans tous les tissus cibles concernés par la reproduction. En l'absence d'hormone, ce récepteur, membre de la superfamille des récepteurs nucléaires (voir chap. 2, § 4), est intégré au sein d'un complexe constitué de protéines de choc thermique et d'immunophilines. La liaison de l'hormone provoque la dissociation du complexe, l'homodimérisation des récepteurs qui deviennent alors capables de se lier aux séquences d'ADN spécifiques. Une deuxième forme du récepteur (R-E $\beta$ ) vient d'être identifiée, $R-E \alpha$ et $R-E \beta$ lient l'œstradiol avec une affinité comparable $\left(\mathrm{K}_{\mathrm{D}}=0,2-0,5 \cdot 10^{-9} \mathrm{M}\right)$. 


\subsection{LA PROGESTÉRONE}

\subsubsection{Origine et nature de la progestérone}

C'est le précurseur de toutes les hormones stéroïdes. La synthèse s'arrête à ce stade dans les cellules du corps jaune ovarien dont elle constitue l'hormone essentielle. L'ovaire est relayé par le placenta au $2^{\mathrm{e}}$ mois de la grossesse, ce qui entraîne l'involution du corps jaune gravidique.

Il est possible d'obtenir de la progestérone :

- à partir du corps jaune de baleine, ou

- à partir du stigmastérol extrait des graines de soja ;

- par biosynthèse (voir chap. 1, § 7.3).

L'ovaire sécrète encore deux autres substances progestagènes chez la femme : les $20 \alpha$ - et $20 \beta$-hydroxyprogestérones.

\subsubsection{Catabolisme de la progestérone}

Elle est très rapidement détruite, essentiellement par le foie. Les métabolites qui ont un $\mathrm{OH}$ en $3 \alpha$ sont la prégnénolone (5\%) et le prégnandiol (95\%), qui passent dans l'urine sous forme glucurono-conjuguée.

\subsubsection{Actions physiologiques de la progestérone}

- Sur l'utérus : elle forme la dentelle endométriale, après sensibilisation de l'utérus par les œstrogènes. Les glandes deviennent flexueuses, riches en glycogène. L'activité contractile du myomètre diminue.

La progestérone rend ainsi la muqueuse utérine apte à la nidation et au maintien de la gestation.

Au niveau du col utérin, la glaire cervicale se transforme dès l'ovulation en un bouchon opaque de coagulum glaireux qui empêche la pénétration utérine d'éventuels spermatozoïdes. La progestérone agit en inhibant la sécrétion des glandes de l'endocol.

- Sur les trompes utérines : le déficit de progestérone accélère le transit tubaire, alors qu'un excès en progestérone le retarde; dans les deux cas, on aboutit à une infertilité par anomalie de la nidation.

- Sur l'ovaire : sécrétée sous l'influence de la LH, la progestérone induit spécifiquement l'ovulation.

Administrée dès le début du cycle, elle entraîne une inhibition, par feed-back, de la sécrétion des gonadostimulines et la mise au repos de l'ovaire (principe des contraceptifs).

- Sur le vagin : on observe sous l'effet de la progestérone la prolifération des cellules épithéliales non-kératinisées et l'apparition de leucocytes (chez les Rongeurs). 
- Sur les glandes mammaires : la progestérone provoque la croissance des acini.

- Sur la température de base : un décalage thermique, par remontée de la température et maintien en plateau au-dessus de $37^{\circ} \mathrm{C}$, résulte de l'action thermogénique de la progestérone. Il est le témoin de l'ovulation. L'élévation de la température est de l'ordre de 5/10 de degré.

\subsubsection{Dosage de la progestérone}

- Au cours du cycle œstrien

- en phase folliculaire : 630 à 5100 pmol $=0,2$ à $1,6 \mu \mathrm{g} / 1$;

- en phase post-ovulatoire : 31000 à 54000 pmol/1 = 10 à $17 \mu \mathrm{g} / 1$

- Au cours de la grossesse

- 17 à 18 semaines : $95000 \mathrm{pmol} / 1$;

- 28 à 30 semaines : $207000 \mathrm{pmol} / 1$;

- 38 à 40 semaines : $382000 \mathrm{pmol} / 1$.

\subsection{LES HORMONES ANDROGÈNES CHEZ LA FEMME}

Le taux de production de la testostérone chez la femme est de l'ordre de $0,4 \mathrm{mg} / 24 \mathrm{~h}$. La moitié de ce taux correspond à la conversion périphérique de la $\Delta 4$-androstènedione au niveau du foie et du sang, $10 \%$ proviennent de la surrénale et $40 \%$ de l'ovaire. La $\Delta 4$-androstène-dione est à $80 \%$ d'origine glandulaire, mixte ovarienne et surrénalienne.

La déhydro-épiandrostérone provient essentiellement de la surrénale.

\subsection{TRANSPORT PLASMATIQUE DES HORMONES OVARIENNES}

Ces hormones sont de petites molécules et leur transport plasmatique nécessite un couplage avec une protéine de transport qui est plus ou moins spécifique :

- Deux protéines spécifiques de haute affinité $\left(\mathrm{K}_{\mathrm{D}}<0,1 \mu \mathrm{M}\right)$ et de faible capacité de transport :

- CBG (corticosteroid binding globulin ou transcortin) liant les stéroïdes en C21 avec une structure $\Delta 4-3$, céto (cortisol, corticostérone, progestérone, 17-hydroxyprogestérone). C'est une $\alpha$-glycoprotéine de PM 25000 . Son $K_{D}$ est de l'ordre de $10^{-8} \mathrm{M}^{8}$.

- SBG (sex hormone binding globulin) liant l'œstradiol, la testostérone (dite aussi SHBG ou SBGF ou TeBG). C'est une $\beta$-glycoprotéine de PM 50000 à 100000 . Elle est sécrétée par le foie.

8 L'élévation du taux de la transcortine au cours de la gestation, sous l'effet des œstrogènes, augmente la quantité de progestérone liée. En effet la progestérone, pendant la grossesse, circule essentiellement liée à la transcortine. 
Les œstrogènes et les hormones thyroïdiennes stimulent la production hépatique de SBG et les androgènes semblent l'inhiber.

L'affinité de liaison des œstrogènes pour la SBG est deux fois moindre que celle de la testostérone ou de la dihydrotestostérone. La $\Delta 4$-androstène-dione et la déhydro-épiandrostérone ne sont pas, ou peu, liées par la SBG.

- Une protéine non-spécifique, l'albumine, qui lie de façon non-spécifique tous les stéroïdes, avec une faible affinité et une très grande capacité. Une concentration 1000 à 100000 fois plus élevée $(40 \mathrm{~g} / 1)$ mais une constante de dissociation entre $1 \mu \mathrm{M}$ (œstrogènes) et $1 \mathrm{mM}$ (cortisol).

- Des protéines propres à certaines espèces, et dans certaines situations physiologiques, par exemple la PBP (progesterone binding plasma protein) présente chez le cobaye gestant. Il est à noter que seule la fraction libre de l'hormone est active au niveau des cellules cibles.

\section{LE CYCLE MENSTRUEL OU CYCLE CESTRIEN}

Il représente l'ensemble des modifications cycliques qui se manifestent chez la femme tous les 28 jours, de la puberté à la ménopause (voir fig. 12.6).

En général, il s'installe progressivement en 6 à 12 mois, vers la $12^{\mathrm{e}}$ année, se régularise ensuite pour rester stable jusque vers 40-50 ans, âge habituel du début de la ménopause, s'arrête de façon plus ou moins capricieuse vers 50 ans, âge moyen de l'arrêt des règles.

Chez la femme jusqu'à la ménopause, il se manifeste par des modifications répétitives avant et après l'ovulation : du $1^{\mathrm{er}}$ au $14^{\mathrm{e}}$ jour c'est la phase folliculaire ${ }^{9}$, pendant laquelle le follicule arrive à maturité ; du $14^{\mathrm{e}}$ au $28^{\mathrm{e}}$ jour, caractérisé par l'activité endocrine du corps jaune, c'est la phase lutéale.

L'anœstrus caractérise l'état du tractus génital féminin, avant la maturité sexuelle, après castration, après la ménopause, entre deux cycles espacés ou, à un degré moindre, lorsqu'il existe une carence ovarienne plus ou moins profonde.

\subsection{LE CYCLE OVARIEN}

Il comporte des variations histocytologiques et hormonales caractéristiques (voir fig. 12.8).

Lors de la phase folliculaire, l'évolution terminale de la folliculogenèse aboutit au follicule mûr de de Graaf. L'hormonosécrétion est principalement œstrogénique avec

9 Arbitrairement, le $1^{\text {er }}$ jour des règles est considéré comme le $1^{\text {er }}$ jour du cycle. 
des taux d'œstradiol de l'ordre de $100 \mathrm{pg} / \mathrm{ml}$ et un pic avoisinant $300 \mathrm{pg} / \mathrm{ml}$ vers le $10^{\mathrm{e}}$ jour, juste avant l'ovulation qui a lieu en principe vers le $14^{\mathrm{e}}$ jour, terme de cette première phase du cycle.

Lors de la phase lutéale, le follicule a laissé sa place au corps jaune qui va durer, hors grossesse, de 10 à 12 jours. Les œstrogènes continuent d'être sécrétés au taux approximatif de 150 à $200 \mathrm{pg} / \mathrm{ml}$; la progestérone augmente rapidement dès l'ovulation avec un maximum de $10 \mathrm{ng} / \mathrm{ml}$ vers le $21^{\mathrm{e}}$ jour. Ces taux sont variables selon la qualité du corps jaune considéré.

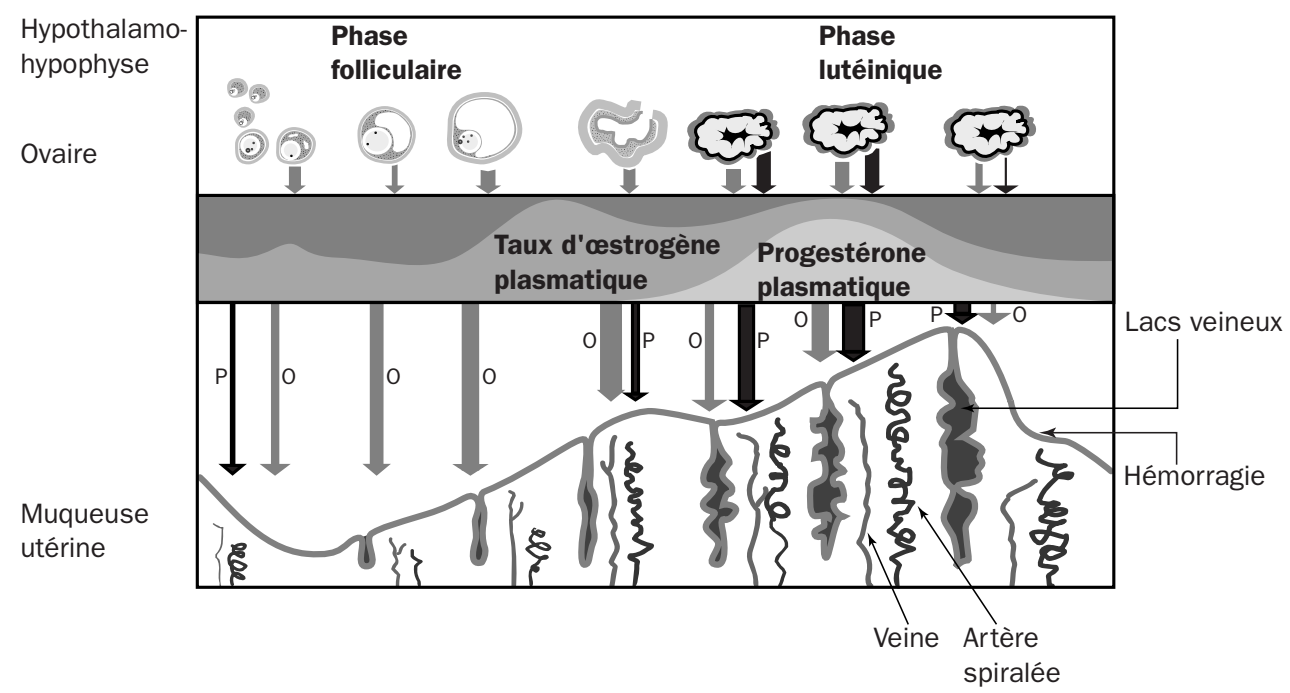

a - Les différentes phases du cycle

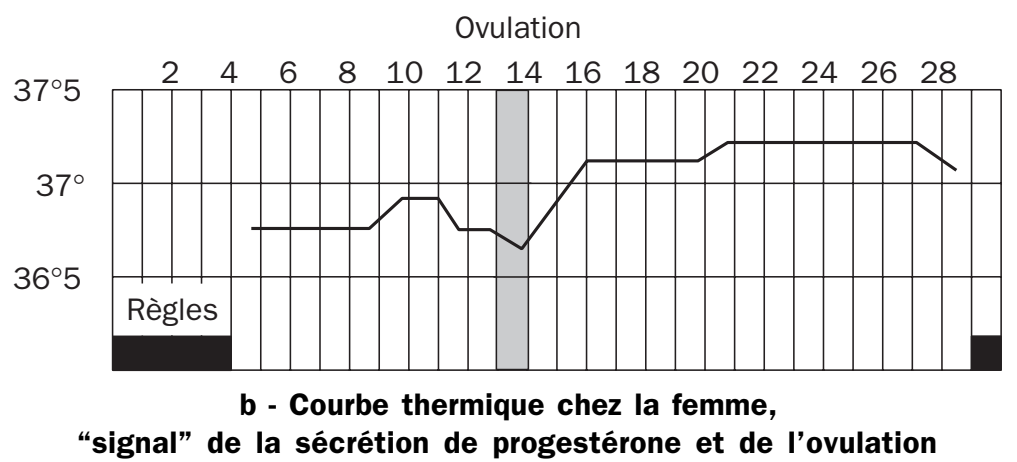

Figure 12.6 - Le cycle menstruel

\subsection{LE CYCLE UTÉRIN}

Sous l'influence des hormones ovariennes, la muqueuse utérine, pratiquement abrasée par les règles, va restaurer son épaisseur sous l'influence des œstrogènes en première phase, lutéiniser l'endomètre en deuxième phase, réalisant la "dentelle utérine" très propice à une éventuelle implantation de blastocyste. 
Au niveau du col, l'hormonosensibilité se manifeste par une augmentation progressive de la filance de la glaire cervicale qui va cristalliser en "feuilles de fougère" vers le 14 e jour, période la plus favorable à la pénétration spermatique. Cette même glaire, l'ovulation accomplie, va se coaguler en un bouchon intra-cervical, le bouchon muqueux, protégeant la cavité utérine contre d'éventuelles agressions microbiennes, ou autres, issues du vagin.

\subsection{LE CYCLE VAGINAL}

De la même façon, il existe un cycle vaginal. L'hormonodépendance de la muqueuse se manifeste par son degré et son type de desquamation. Les frottis vaginaux (F.V.), principalement utilisés pour le dépistage du cancer du col de l'utérus, révèlent également la qualité de l'imprégnation hormonale.

En post-règles, anœstrus, prépuberté ou post-ménopause, les F.V. montrent surtout des cellules basales ou parabasales à cytoplasme basophile et gros noyau. Lors de la phase folliculaire, l'augmentation du nombre des cellules éosinophiles à petit noyau est le garant d'une bonne restauration de la muqueuse vaginale et endométriale. En phase lutéale, des F.V. "sales" avec de nombreux polynucléaires, des cellules plicaturées dites "naviculaires" reflètent une imprégnation hormonale, de type progestatif, satisfaisante.

\subsection{LES MODIFICATIONS CYCLIQUES EXTRAGÉNITALES}

D'autres modifications cycliques, extragénitales, sont bien connues : le gonflement mammaire douloureux avant les règles (mastodynies prémenstruelles), les rétentions d'eau et de sels minéraux, les modifications thermiques dues à l'effet hyperthermisant des progestatifs du corps jaune ${ }^{10}$, les troubles de l'humeur... Toutes ces manifestations, de même que l'ostéoporose de l'anœstrus, sont le témoin de l'effet systémique des sécrétions ovariennes sur de nombreux récepteurs centraux et périphériques.

\subsection{LA MENSTRUATION ET SON DÉTERMINISME (fig. 12.7)}

La menstruation, en raison de son importance, mérite une place particulière. Elle correspond à la desquamation de la partie superficielle de l'endomètre; elle s'accompagne d'ordinaire d'une perte sanguine de 60 à $100 \mathrm{ml}$ répartie sur 5 jours.

Son déterminisme est de nature hormonale, c'est l'imprégnation œstroprogestative séquentielle qui engendre l'œdème endométrial, l'ischémie relative des couches superficielles de l'endomètre et la nécrose menstruelle. La privation hormonale brutale

10 Un décalage thermique de 4 à $5 / 10^{\mathrm{e}}$ de degré est contemporain de l'ovulation (fig. 12.6.b). La persistance du décalage témoigne de la bonne activité fonctionnelle du corps jaune. 
contemporaine de la lutéolyse joue également un rôle en engendrant les spasmes des vaisseaux spiralés et les plages d'ischémie avec nécrose de l'endomètre fonctionnel. De ce fait, on conçoit en clinique humaine le traitement des dysménorrhées par insuffisance lutéale et l'effet heureux des progestatifs sur la douleur.

Chez la plupart des Mammifères, les modifications cycliques du tractus génital sont tout à fait comparables au cycle menstruel de la femme. Cependant, l'ovulation ou œstrus s'accompagne de "chaleurs" et la phase folliculaire prend le nom de proœstrus, alors que la phase lutéale se décompose en di-œstrus I correspondant au corps jaune fonctionnel et di-œstrus II caractéristique de la régression du corps jaune.

a

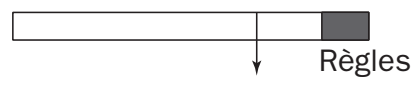

Ovariectomie

b

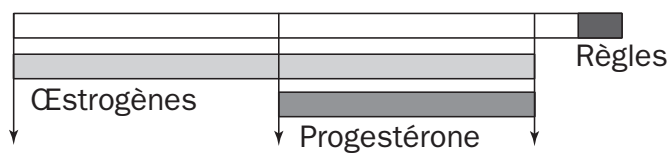

Ovariectomie

C

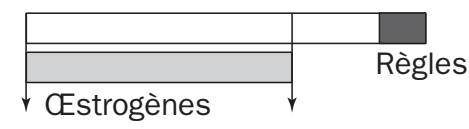

Ovariectomie

Arrêt des

œstrogènes

d

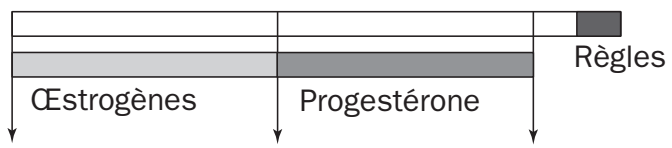

Ovariectomie

Arrêt des

Arrêt de la

œstrogènes

progestérone

Femme normale

e

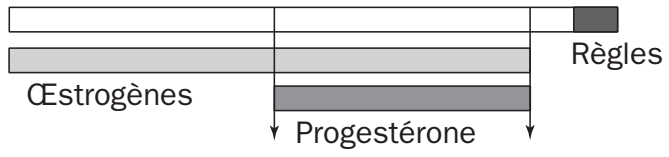

Ovulation

Figure 12.7 - Déterminisme de la menstruation

On peut faire apparaître la menstruation chez l'animal (guenon) après ovariectomie (a) ou imprégnation hormonale; l'association œstrogènes + progestérone $(b, d)$ entraîne, dès son arrêt, une menstruation plus précoce qu'avec les œstrogènes seuls (c). 


\subsection{LE CONTRÔLE NEURO-ENDOCRINIEN DU CYCLE ESTRIEN}

\subsubsection{Caractères généraux}

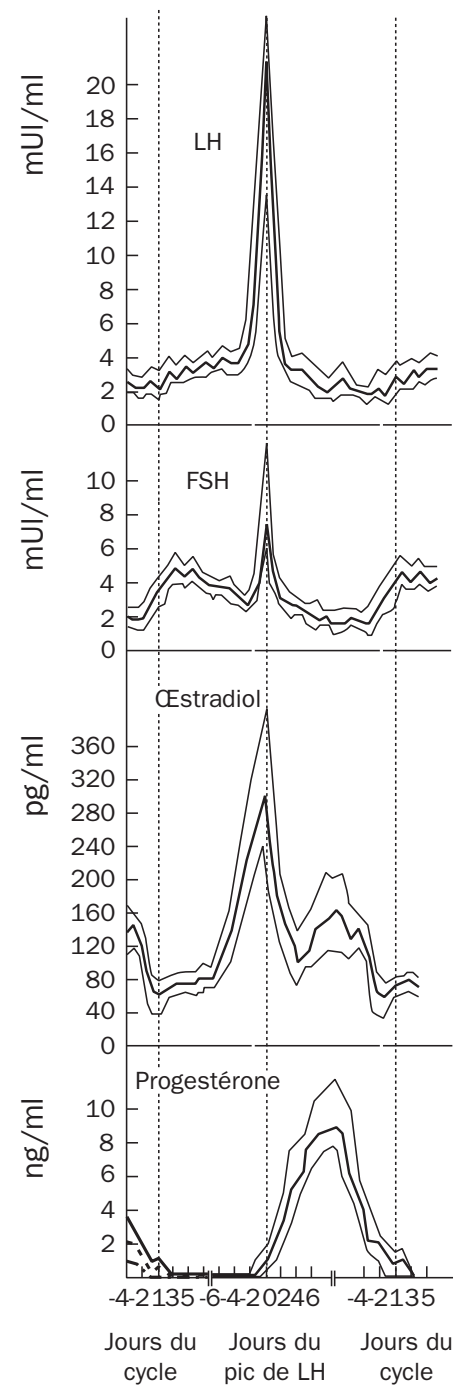

Figure 12.8 - Les hormones du cycle menstruel chez la femme (d'après Rotten et coll., 1985)
L'activité ovarienne est soumise à un contrôle hormonal multifactoriel dans lequel s'intègrent les activités de l'hypothalamus, de l'hypophyse et de l'ovaire lui-même (fig. 12.8).

L'hypothalamus produit une gonadolibérine, la GnRH ou LH-RH, qui va agir sur la synthèse et la libération des gonadotrophines hypophysaires.

L'hypophyse sécrète trois hormones gonadotropes : FSH, LH et LTH ou Prl. La sécrétion de FSH présente, par rapport à une sécrétion de base d'environ $3 \mathrm{mUI} / \mathrm{ml}$ de plasma, une élévation dans la première partie de la phase folliculaire, un pic à $8 \mathrm{mUI} / \mathrm{ml}$, synchrone de celui de LH vers le 13 e jour du cycle et un taux relativement bas en phase lutéale avec toutefois une légère remontée en fin de cycle.

LH a une sécrétion de base de l'ordre de $3 \mathrm{mUI} / \mathrm{ml}$, présente vers le $13^{\mathrm{e}}$ jour une ascension importante de ses taux : la décharge ovulante qui précède l'ovulation de 37 à $40 \mathrm{~h}$.

LTH (prolactine) favorise chez les rongeurs la sécrétion et le maintien du corps jaune. On détecte en effet, chez le rat, un pic de LTH synchrone de celui de LH. Chez les primates, en revanche, l'activité gonadotrope de la prolactine est discutée, bien que le corps jaune humain possède des récepteurs à LTH et que ceux-ci soient stimulés par LH. On s'accorde actuellement pour attribuer à la prolactine un rôle de potentialisation de l'effet LH sur la sécrétion progestative en normo-prolactinémie.

A ce titre, la LTH ferait partie du complexe lutéotrophique. En revanche, en cas d'hyperprolactinémie, la LTH entraînerait une inhibition ovarienne, témoin le syndrome d'aménorrhée-galactorrhée dans lequel des taux excessifs de prolactine engendrent un blocage ovarien complet.

Au niveau de l'ovaire, les gonadotrophines agissent sur la thèque et la granulosa, ainsi que sur le corps jaune et le stroma. 
FSH a des récepteurs sur les cellules de la granulosa où elle induit ses propres récepteurs, la synthèse de l'inhibine, les enzymes de l'aromatisation des androgènes et, en fin de phase folliculaire, les récepteurs à LH.

LH a des récepteurs sur la thèque interne pendant toute la durée du cycle, elle y induit la synthèse des androgènes et des œstrogènes. Sur la granulosa, elle possède également ses propres récepteurs et y détermine la diminution de ceux de FSH. En phase lutéale, les récepteurs de LH sont présents et l'activité fonctionnelle du corps jaune est en relation directe avec cette gonadotrophine. Enfin, la LH induit la synthèse des androgènes par le stroma ovarien.

Au total, ceci permet de construire les séquences fonctionnelles synergiques suivantes (fig. 12.9).

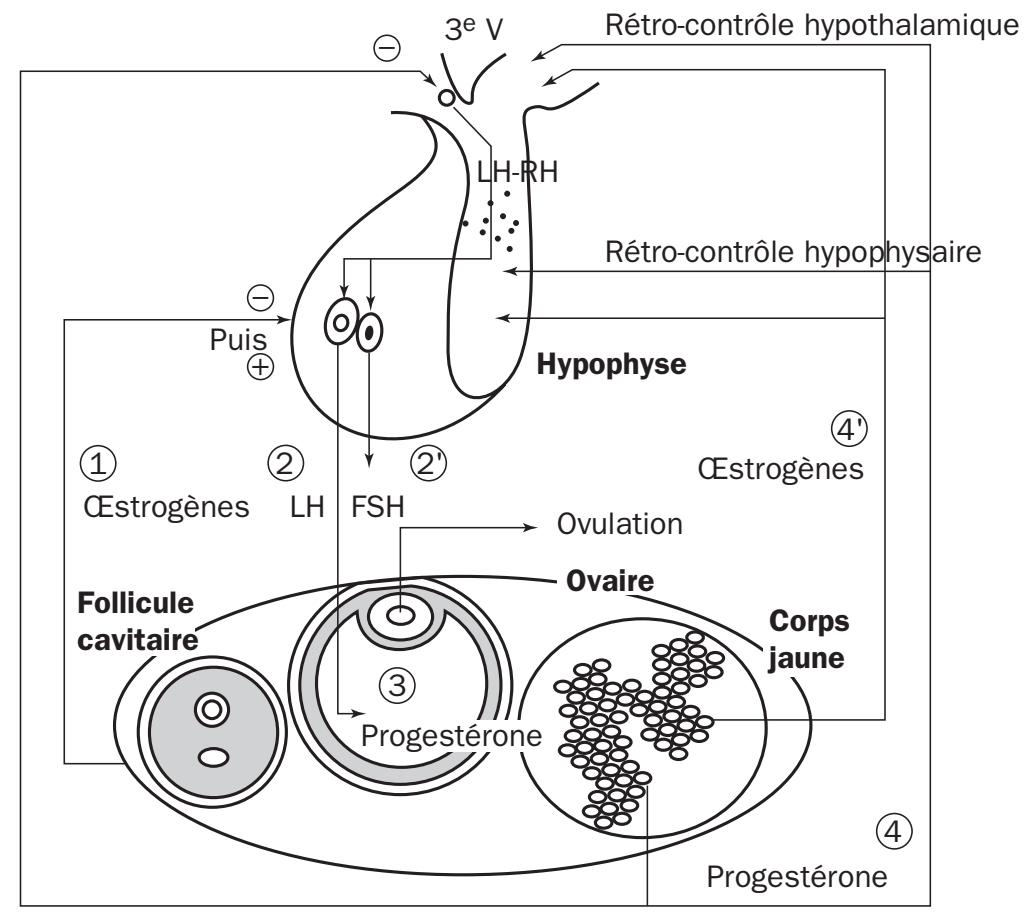

Figure 12.9 - Le rétro-contrôle hormonal dans le cycle œstrien

La sécrétion d'œstrogènes par l'ovaire (1) exerce un effet inhibiteur sur la sécrétion de FSH (rétro-contrôle ou feed-back négatif) puis, à partir d'un certain taux, provoque la décharge de $\mathrm{LH}$ (2) et FSH (2') (rétro-contrôle positif). La décharge de LH provoque la sécrétion de progestérone par les cellules de la granulosa (3), qui vont se transformer en cellules lutéiniques, et l'ovulation. La sécrétion de progestérone par les cellules lutéiniques (4) exerce un effet inhibiteur sur les neurones hypothalamiques à LH-RH (rétro-contrôle négatif) et, avec les œstrogènes qui continuent d'être sécrétés par le corps jaune (4'), un autre rétro-contrôle, au niveau hypophysaire, sur LH et FSH respectivement. 


\subsubsection{Contrôle de la phase folliculaire}

La LH induit la synthèse des androgènes au niveau de la thèque interne. La FSH, via ses effets stimulant la production d'aromatases (enzymes provoquant l'aromatisation du cycle A) par la granulosa, entraîne leur transformation en ostrogènes. Comme la FSH détermine ses propres récepteurs, cette aromatisation est auto-entretenue, de même que les effets des œstrogènes stimulant la prolifération folliculaire.

Le follicule de de Graaf dominant, riche en récepteurs R-FSH, sécrète des taux d'œstradiol importants qui entraînent un rapport E2 / androgènes plus élevé que celui des autres follicules recrutés ; de ce fait, ces derniers sont voués à l'atrésie.

Des rétro-contrôles limitent ces actions : d'une part, les œstrogènes vont faire diminuer la sécrétion de FSH et, d'autre part, exercer un effet positif sur l'excrétion de LH hypophysaire (voir fig. 12.9). Ainsi, les œstrogènes pré-ovulatoires vont conditionner la décharge ovulante de LH, pendant que l'œstradiol et l'inhibine vont assurer le rétro-contrôle négatif de FSH.

\subsubsection{Contrôle de la phase lutéale}

La LH détermine et entretient la sécrétion majoritairement progestative du corps jaune. La progestérone a le pouvoir de bloquer la croissance d'autres follicules et, en outre, inhibe sa propre sécrétion. Ainsi, par ce rétro-contrôle hypophysaire négatif, le corps jaune s'autorégule. Enfin, la progestérone, en stimulant la production de FSH hypophysaire, amorce le cycle suivant.

\section{PARTiCularités de L'OVUlation ET DE LA PHASE LUTÉINIQUE CHEZ DIFFÉRENTS MAMMIFÈRES}

Chez les Mammifères, le nombre des ovules émis paraît de plus en plus limité à mesure que les chances de survie du jeune deviennent plus grandes :

- un œuf par ovulation dans l'espèce humaine (soit 400 à 500 ovules pondus sur 500000 environ présents dans l'ovaire de la jeune fille) ;

- généralement un seul œuf par ovulation chez la vache ;

- une douzaine d'œufs chez la truie ;

- 500 œufs par an chez la grenouille (la ponte est saisonnière) ;

- et, au cours de sa vie entière :

- 5 à 10 millions d'œufs chez l'anguille ;

- 10 millions d'œufs chez une reine de termites ;

- 60 millions d'œufs chez une femelle d'ascaris.

Chez de nombreuses espèces, l'ovule s'entoure au cours de son cheminement d'enveloppes protectrices ou membranes (membranes secondaire et tertiaire). La membrane primaire est la membrane vitelline, sécrétée par la couche de cellules folliculaires. 
Chez les Batraciens, se différencient autour de la membrane vitelline le chorion et la gangue muqueuse. Chez les Sauropsidés (Reptiles et Oiseaux), se constitue une coque, molle chez les Reptiles, mieux calcifiée chez les Oiseaux.

Le cycle œstrien présente des variations remarquables selon les Mammifères.

Deux types s'opposent presque, que nous proposons de qualifier de "cigale" et de "fourmi".

- Le type "cigale" est représenté par la femme qui, de toute façon, qu'il y ait rapport sexuel ou pas :

- présente une ovulation ;

- accomplit une phase lutéinique complète avec, à chaque fois, le développement d'une "dentelle" utérine complète qui permettrait une nidation. Remarquons, en outre, que la femme est le seul Mammifère qui accepte le mâle à n'importe quel moment de son cycle œstrien.

- Le type "fourmi" est représenté par la lapine, mais aussi la chatte et le furet. Deux cas de figure sont possibles, qui constituent chaque fois une économie de sécrétions hormonales et de modifications sexuelles superflues :

- pas de coït, pas d'ovulation : l'ovulation est dite "provoquée", c'est un mécanisme nerveux qui déclenche la décharge de LH-RH et donc le pic de LH ;

- après ovulation provoquée, deux éventualités sont possibles :

- le rapport n'est pas fécondant, le corps jaune est dit pseudo-gestatif et ne dure, chez la lapine, que 16-17 jours ;

- le rapport est fécondant, le corps jaune est gestatif et dure chez la lapine 3032 jours.

- La rate constitue un cas intermédiaire. C'est un animal à ovulation périodique, comme la femme. Mais la durée de la phase lutéinique varie selon qu'il y a ou non présence de mâle(s). Trois cas de figure sont alors possibles :

- pas de mâle(s) : ovulation périodique tous les 4 ou 5 jours (selon l'animal). La phase lutéinique, qui dure moins de 3 jours, ne développe pas une "dentelle" propre à la nidation.

- coït non-fécondant : le corps jaune pseudo-gestatif dure 13-15 jours.

- coït fécondant : le corps jaune gestatif dure 22 jours.

\section{RÉGULATION DE LA FONCTION GONADOTROPE FEMELLE}

\subsection{INFLUENCE DES HORMONES OVARIENNES (voir fig. 12.9)}

L'ovariectomie ou la ménopause provoquent une augmentation de la FSH et de la LH. L'œstradiol exerce en effet un contrôle inhibiteur tonique (rétro-contrôle négatif) sur la sécrétion des cellules gonadotropes hypophysaires. La sécrétion de FSH est plus affectée que celle de LH (voir (4') dans la fig. 12.9). 
L'augmentation de la durée d'imprégnation et des concentrations sériques d'œstradiol provoque au contraire une élévation du taux de FSH et de LH (rétro-contrôle positif), qui s'accroît à mesure que le taux d'œstradiol plasmatique augmente et que l'on s'approche de l'ovulation. Cette sensibilisation hypophysaire ne se concrétise qu'après un délai d'au moins $60 \mathrm{~h}$, même avec des concentrations d'œstradiol de l'ordre de $300 \mathrm{pg} / \mathrm{ml}$. Le délai serait de 5 à 6 jours avec une concentration de $90 \mathrm{pg} / \mathrm{ml}$.

Il est possible que cette réponse paradoxale s'explique par la présence de deux types de neurones hypothalamiques.

La progestérone inhibe essentiellement la LH (voir (4) dans la fig. 12.9). C'est sur ce dernier phénomène qu'est fondée la pilule anti-ovulatoire, qui comporte toujours un dérivé synthétique de la progestérone. Elle contient également une faible dose d'œstrogènes, qui assure une meilleure trophicité du tractus génital et évite souvent des troubles secondaires (métrorragies).

\subsection{RAPPORTS HYPOTHALAMO-HYPOPHYSAIRES}

La section de la tige pituitaire provoque l'arrêt du cycle œstrien et la disparition de la sécrétion de FSH et de LH.

Nous avons vu (voir le complexe hypothalamo-hypophysaire) que les relations hypothalamo-hypophysaires sont réalisées par des facteurs sécrétés par les neurones hypothalamiques :

- pour FSH et LH : un facteur unique, la LH-RH ${ }^{11}$ (ou GnRH, ou gonadolibérine), décapeptide dont l'action déclenchera la décharge de FSH ou de LH au niveau de l'hypophyse, selon le taux d'hormones sexuelles présentes dans le sang, l'excès d'œstrogènes favorisant la décharge de LH. Chez le singe, ce facteur a été retrouvé dans trois régions de l'hypothalamus : le noyau supra-optique, le noyau arqué ${ }^{12}$ et le corps mamillaire.

- pour la prolactine : un facteur inhibiteur (PIF) qui présente un précurseur commun avec la GnRH. Mais il faut tenir compte surtout de l'action inhibitrice des neurones dopaminergiques issus de la région médioventrale du tuber. Enfin la TRH a un effet stimulant sur la sécrétion de prolactine.

11 Le taux de LH-RH dans le sang du système porte varie de 200 à 800 pg / ml. Dans le sang périphérique, le taux serait voisin de $1-2 \mathrm{pg} / \mathrm{ml}$ en début de cycle et pourrait aller jusqu'à $2,5 \mathrm{pg} / \mathrm{ml}$ en milieu de cycle.

12 Il est possible d'induire la libération de LH-RH par stimulation électrique de l'hypothalamus médiobasal avec des fréquences de 10 à $100 \mathrm{~Hz}$ (Dyer et coll., 1980). 


\subsection{PUlSATILITÉ deS SÉCRÉTIONS DE LA LH-RH ET DES HORMONES GONADOTROPES}

La LH-RH est sécrétée par le noyau arqué de façon pulsatile (Ferin et coll., 1984 ; Rotten, 1985), à raison d'une pulsation toutes les 60 à 90 min ; cette pulsatilité est nécessaire au bon fonctionnement des sécrétions gonadotropes de LH et FSH, qui sont également sécrétées de façon pulsatile, en plus de leur variation cyclique dans le cycle œstrien (fig. 12.10 et 12.11).

On a pu démontrer que chaque oscillation sécrétoire ("pulse") de LH est immédiatement précédée d'une oscillation synchrone de $\mathrm{LH}$ RH (fig. 12.12 et 12.13). La neutralisation de la LH-RH par un anticorps anti-LH-RH supprime la sécrétion pulsatile de $\mathrm{LH}$.

Chez les Primates, le rôle de la LH est essentiellement "permissif" sur les sécrétions de LH et de FSH, mais l'essentiel de la régulation des hormones gonadotropes est assuré par rétrocontrôle des œstrogènes (effet biphasique, d'inhibition au début du cycle, puis rétro-contrôle positif de stimulation dans la période "critique" pré-ovulatoire). La prolactine intervient avec l'œstradiol dans la modulation de l'action de GnRH sur ses récepteurs.

L'utilisation de ces données en thérapeutique a permis le traitement de certaines stérilités par dérèglement hormonal, à l'aide d'une pompe pulsatile à LH-RH.
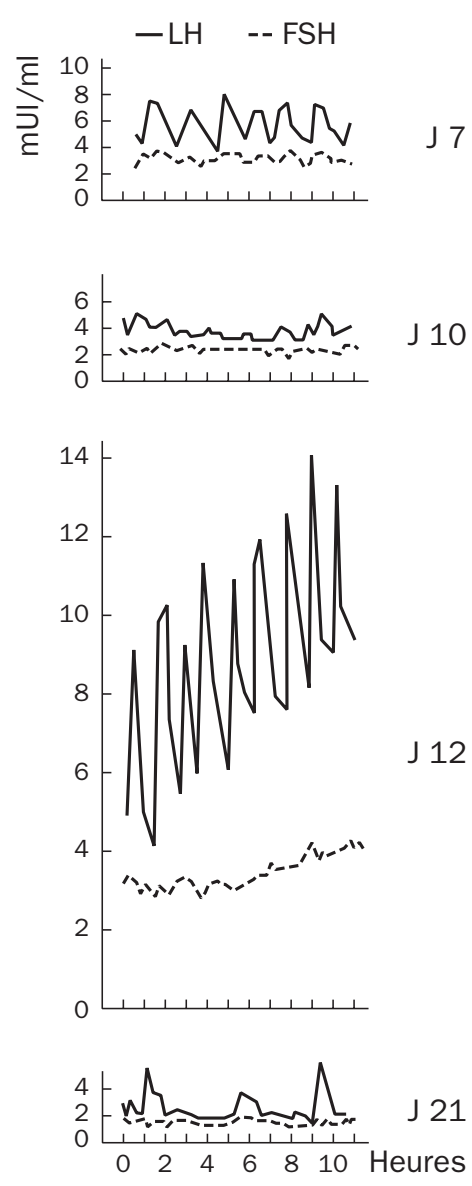

Figure 12.10 - Evolution de la pulsatilité des gonadotrophines au cours du cycle menstruel chez la femme

(d'après Rotten et coll., 1985)

\subsection{LEPTINE ET RÉGULATION DE L'AXE REPRODUCTEUR}

La leptine est une hormone sécrétée par les cellules adipeuses. Sa sécrétion est pulsatile, modulant un rythme circadien avec un pic le matin et un nadir (minimum) l'après-midi (Matkovic et coll., 1997). C'est, chez les Mammifères, une protéine de $16 \mathrm{kDa}$, apparentée à la famille des cytokines (voir chap. 2, § 2.1.4). Elle agit, par l'intermédiaire de récepteurs disséminés dans l'organisme, sur l'équilibre énergétique et la thermorégulation (en augmentant les dépenses énergétiques et la thermogenèse). 


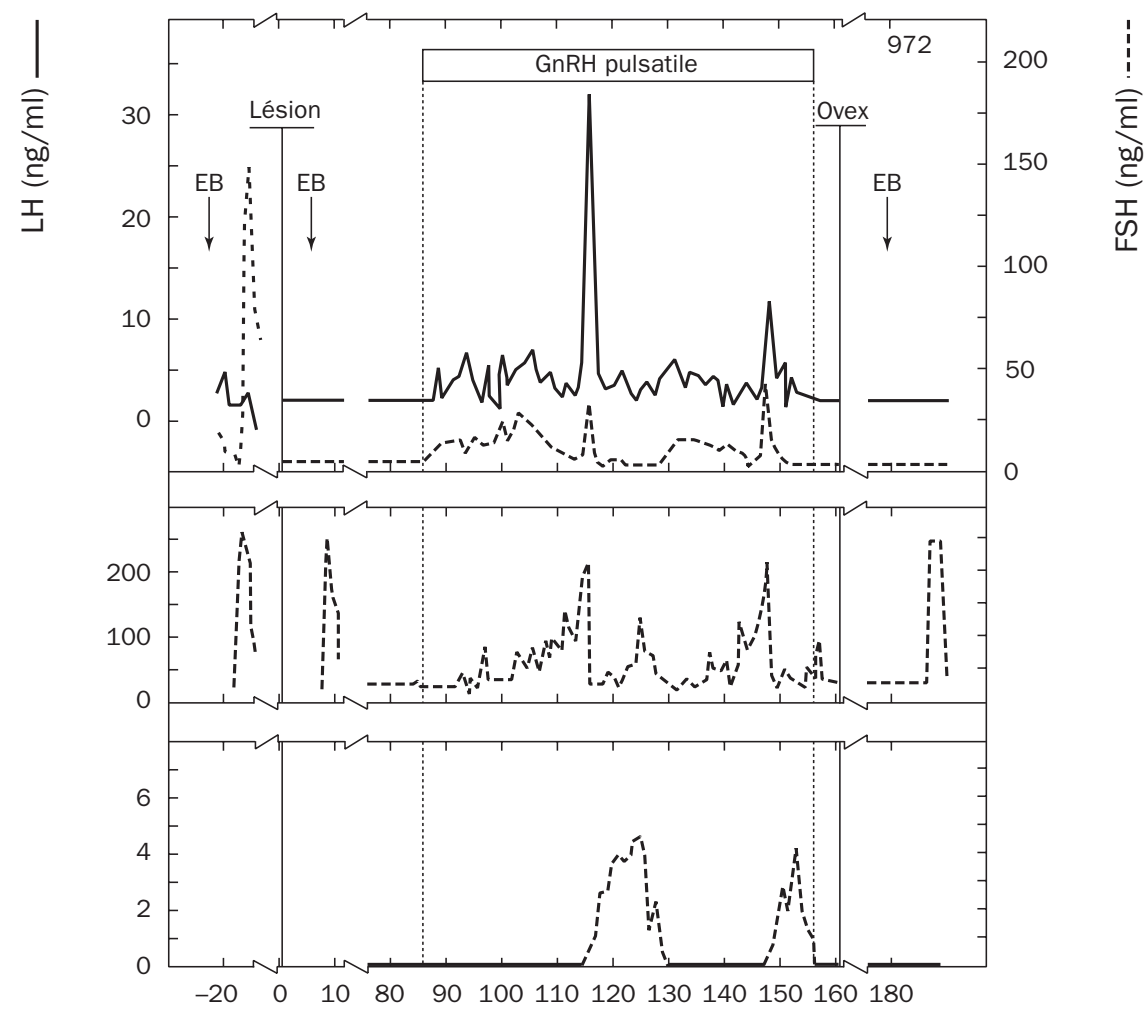

a - Action de la perfusion pulsatile de la GnRH

EB : benzoate d'œstradiol ; Ovex : ovariectomie. après déconnection hypothalamo-hypophysaire

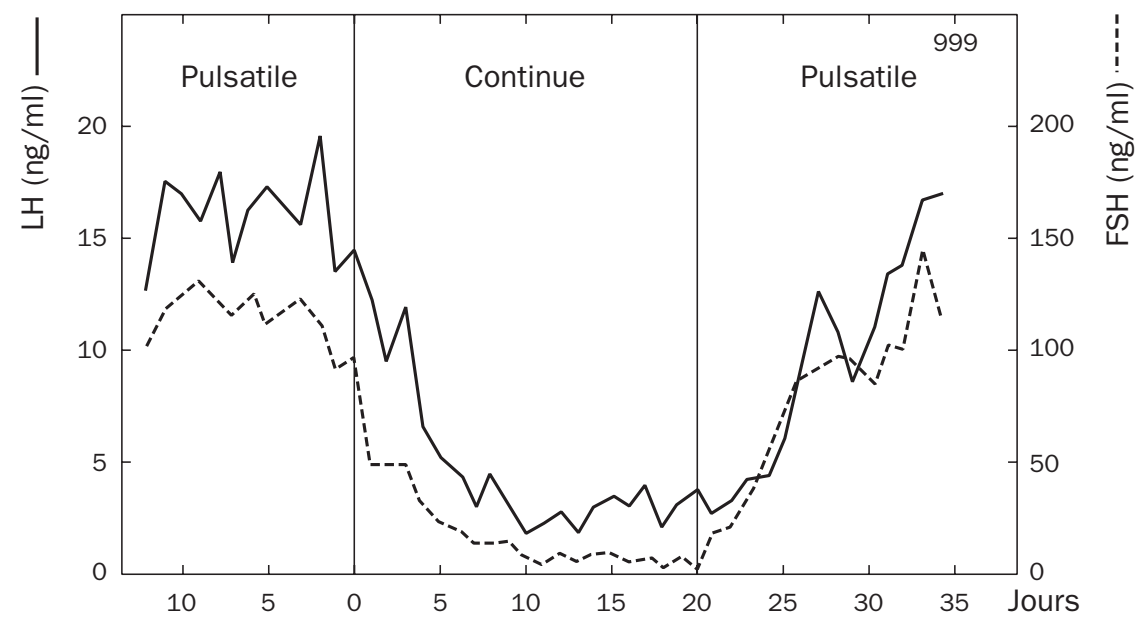

b - Action de la perfusion continue de la GnRH après lésion du noyau arqué

Figure 12.11 - Contrôle neuro-endocrine du cycle menstruel chez le singe rhésus (d'après Knobil, 1980) 


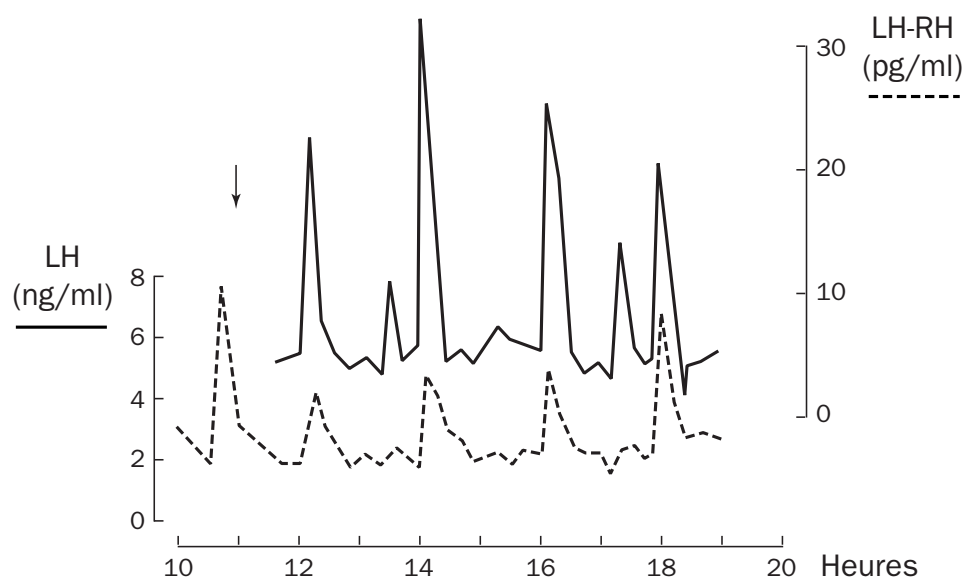

Figure 12.12 - Mesures simultanées de la LH dans la veine jugulaire et de la LH-RH dans le sang hypophysaire portal d'une brebis ovariectomisée (d'après Clarke et Cummins, 1982)

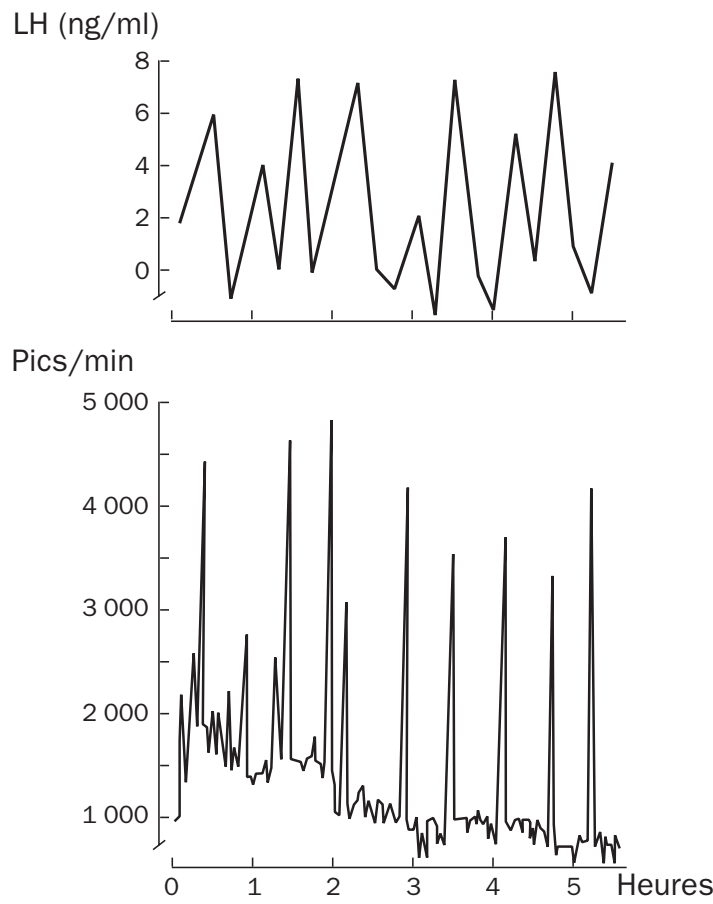

Figure 12.13 - Enregistrement comparé (sous anesthésie) de l'activité électrique (pics / min) dans le noyau arqué et des taux de LH dans le sang périphérique de rates ovariectomisées (d'après Kawakami et coll., 1982) 
C'est également un facteur satiétogène, par inhibition de l'expression hypothalamique du neuropeptide Y (NPY) qui est un stimulateur de l'appétit. L'activation de la protéine STAT3 (signal transducers and activators of transcription 3) semble être la première étape qui suit la liaison de la leptine à son récepteur hypothalamique.

L'ensemble de ces actions conduit à une perte de poids corporel. Le rôle de la leptine fut découvert grâce à l'étude des souris $o b / o b$, homozygotes pour une mutation du gène de la leptine, qui étaient obèses par incapacité de sécréter de la leptine (Zhang et coll., 1994). Mais la leptine joue un rôle fondamental dans la maturation et le fonctionnement de l'axe reproducteur.

Outre l'obésité, l'hyperglycémie et les troubles de la thermorégulation, les souris $o b / o b$ présentent un hypogonadisme et sont stériles. Chez l'homme, les concentrations de leptine sérique sont corrélées, dans les deux sexes et à tout âge, à l'indice de masse corporelle (body mass index ou BMI), et présentent un dimorphisme sexuel au cours du développement. A partir de l'âge de 12 ans environ, les filles ont des concentrations de leptine plus élevées que les garçons chez l'adulte et au même âge elles sont trois fois plus élevées chez la femme que chez l'homme.

La concentration de leptine varie durant les cycles menstruels : elle est maximale en phase lutéale et minimale en phase folliculaire. Elle augmente également pendant la grossesse et chute après l'accouchement. Une concentration minimale serait nécessaire au maintien des menstruations, la concentration plasmatique de leptine pourrait être le facteur le mieux corrélé à l'aménorrhée chez la femme anorexique.

Plusieurs études suggèrent que la leptine stimule, par l'intermédiaire de son récepteur, la fonction de reproduction en activant la sécrétion de LH-RH (activation rapide de STAT3 et de canaux potassiques dépendant de l'ATP) dont elle réglerait la sécrétion pulsatile. Elle exerce également, mais in vitro, un effet direct sur l'ovaire, par inhibition de la stéroïdogenèse dans les cellules de la granulosa. Ces deux effets contradictoires pourraient s'expliquer par l'existence des deux formes du récepteur, une forme longue présente dans l'hypothalamus mais absente dans l'ovaire où une forme courte a été détectée. Enfin, la leptine semble constituer un facteur permissif du début de la puberté chez les Mammifères ; chez l'homme sa concentration augmente juste avant le début de la montée de la concentration de testostérone (Frühbeck et coll., 1998 ; Van Gaal et coll., 1999).

En conclusion, il semble bien que la sécrétion de la leptine, corrélée à la masse graisseuse corporelle, lui confère un rôle d' "adipostat", capable de renseigner l'hypothalamus de la femelle sur l'état des réserves énergétiques à long terme, et sur leur compatibilité avec la menée à terme d'une gestation et d'une lactation ultérieures (Bruneau et coll., 1999). 


\subsection{RELATION ENTRE LA LH-RH ET SES RÉCEPTEURS HYPOPHYSAIRES}

L'interaction de la LH-RH avec ses récepteurs hypophysaires (haute affinité et nombre limité de ces récepteurs) est nécessaire à l'action de la LH-RH, elle déclenche :

- dans un premier temps, une agrégation des récepteurs occupés ;

- un phénomène calcium-dépendant (l'intervention de l'AMPc n'est pas nettement établie) ;

- puis une internalisation dans la cellule du complexe LH-RH-récepteur.

Le nombre des récepteurs de la LH-RH est maximum chez les Rongeurs le jour du pic d'œstradiol (pro-œstrus), moment où l'hypophyse est la plus sensible à la LH-RH. Il est le plus bas le jour de l'ovulation (œstrus).

Quel que soit le moment du cycle, l'injection préalable de faibles doses de LH-RH augmente la réponse de LH et de FSH à une action ultérieure de la LH-RH. C'est le phénomène d'autosensibilisation, qui traduit une augmentation du nombre des récepteurs sous l'effet de la LH-RH. Ce phénomène s'observe également chez la femme. Au contraire, la présence continue de fortes doses de LH-RH conduit à un effet de désensibilisation ${ }^{13}$, par occupation excessive des récepteurs, qui s'internalisent et rendent la cellule gonadotrope insensible à une nouvelle action immédiate de la LH-RH.

Cela explique l'efficacité de la sécrétion pulsatile de l'hormone hypothalamique et, pour que la cellule fonctionne à un maximum de rendement, il faut que la fréquence des pulses soit synchrone à la vitesse de reconstitution des récepteurs de surface.

\subsection{SÉCRÉTION DE LH-RH ET OPIACÉS}

Les peptides opiacés exercent chez le rat un effet inhibiteur sur la sécrétion pulsatile de LH-RH par les neurones de l'hypothalamus médiobasal (fig. 12.14). C'est vrai pour la morphine, la $\beta$-endorphine, la met-enképhaline et la leu-enképhaline. La naloxone lève cette inhibition (Drouva et coll., 1981).

L'enképhaline et la dynorphine sont présentes dans les noyaux magno-cellulaires (supra-optiques et paraventriculaires), mais le peptide le plus abondant est la $\beta$-endorphine dont les neurones ont leur corps cellulaire dans le noyau arqué et déversent leur produit de sécrétion en de nombreuses régions du cerveau, y compris les noyaux magno-cellulaires et les vaisseaux portes hypophysaires (Finley et coll., 1981).

13 C'est cet effet qui a été observé avec l'utilisation d'agonistes de la LH-RH, tel la busériline. Mis au point avec l'objectif d'améliorer l'induction de l'ovulation, ces agonistes, appliqués en continu pendant tout le cycle, occupent les sites récepteurs à la LH-RH et bloquent l'ovulation. Administrés à partir du milieu du cycle, ils entraînent une lutéolyse. Ils peuvent être utilisés par voie sous-cutanée ou par vaporisation nasale ! 
Le rôle principal des peptides opiacés serait de moduler le feed-back négatif des stéroïdes ovariens sur la sécrétion de LH.

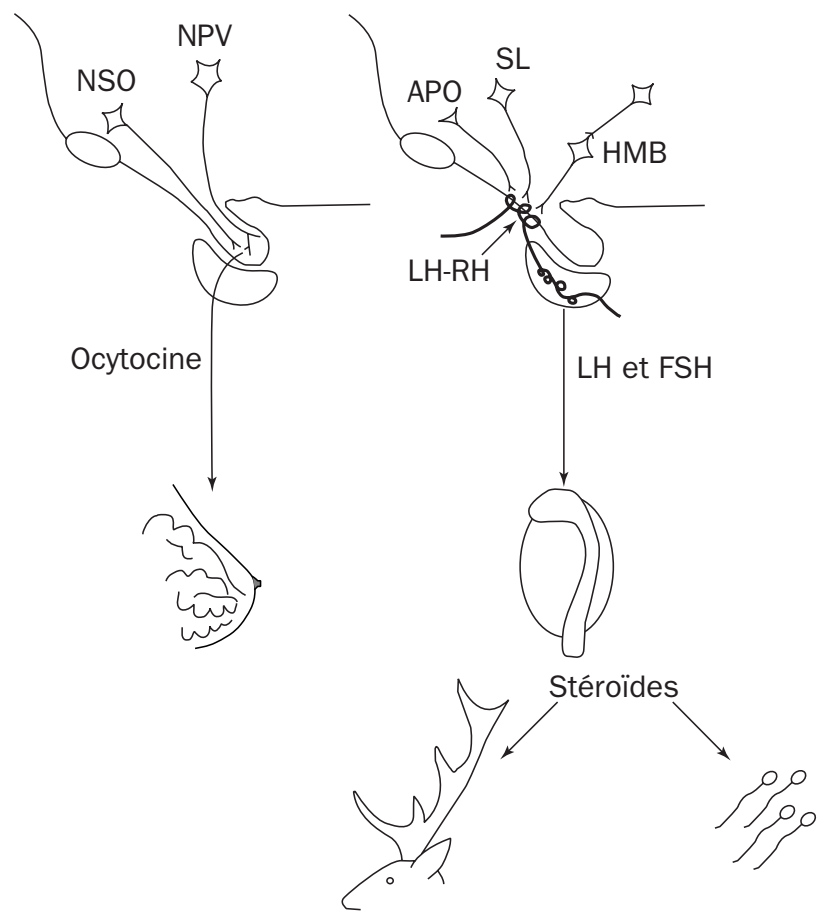

Figure 12.14 - Schéma comparatif des neurones sécréteurs

d'ocytocine et de LH-RH chez les primates (d'après Lincoln et coll., 1985)

$A P O$ : aire pré-optique ; HMB : hypothalamus médiobasal ; NPV : noyau paraventriculaire ; NSO : noyau supra-optique ; SL : septum latéral.

\subsection{LA SEXUALISATION DE L'HYPOTHALAMUS}

L'hypothalamus détermine la caractéristique fondamentale des sécrétions hormonales de l'axe gonadotrope : sécrétion cyclique chez la femelle, sécrétion continue (tonique) chez le mâle (voir chap. 1).

\subsection{LE CERVEAU ET LES HORMONES SEXUELLES}

Des récepteurs d'hormones stéroïdes sont présents dans le tissu cérébral normal, et à des taux beaucoup plus élevés dans les méningiomes (porteurs de récepteurs à hormones sexuelles féminines) et les gliomes (porteurs de récepteurs à androgènes). Plus précisément, on a trouvé (Baulieu et coll., 1987 ; Baulieu, 1991a) de la prégnénolone et de la déhydro-éthylandrostérone dans les oligodendrocytes de la substance blanche et, moins intensément, dans le bulbe olfactif et le cortex entorhinal (neurostéroïdes). Il est possible que ces substances jouent un rôle dans la reconnaissance sexuelle ou dans l'agressivité. 


\subsection{INFLUENCE DE L'ENVIRONNEMENT}

Le fonctionnement génital femelle reste étroitement lié aux conditions extérieures :

- La lumière : elle joue un rôle prépondérant chez les Vertébrés. On connaît le rapport entre la durée de l'éclairement (ou alternance lumière-obscurité) et la ponte chez les Oiseaux. La variation saisonnière de la photopériode conditionne l'activité sexuelle de certaines espèces de Mammifères.

- La température : une ambiance thermique anormale modifie la fertilité chez de nombreuses espèces.

- L'environnement : la captivité, le confinement sont des facteurs importants de stérilité.

- Les facteurs sociologiques et psychologiques : ils sont à l'origine du comportement sexuel de la plupart des espèces.

\section{EXPLORATION DE L'AXE HYPOTHALAMO-HYPOPHYSO-GONADIQUE}

Les renseignements fournis par l'étude des récepteurs périphériques ont l'énorme avantage de montrer une "imprégnation hormonale" globale, qui permet d'ordinaire d'avoir une idée assez exacte de l'état fonctionnel de l'axe hypothalamo-hypophysoovarien. Cependant, les "instantanés biologiques" que représentent les divers dosages peuvent avoir l'intérêt, soit de confirmer une carence légère ou récente, soit de préciser le site en cause.

\subsection{EVALUATION DE LA FONCTION GSTROGÉNIQUE}

En pratique courante, l'évaluation de la fonction œstrogénique comporte le dosage du $17 \beta$-œstradiol, des œstrogènes totaux, ainsi que l'étude de divers métabolites plasmatiques ou urinaires.

\subsection{LA FONCTION PROGESTATIVE}

La fonction progestative, autrefois estimée par le prégnandiol urinaire, est actuellement réalisée à l'aide d'un stéroïdogramme plasmatique qui mesure directement la progestérone, l'hydroxyprogestérone et divers produits dérivés.

\subsection{LA FONCTION ANDROGÉNIQUE}

L'évaluation de la fonction androgénique chez la femme a des indications précises et présente un certain intérêt dans le diagnostic étiologique des hyperandrogénies et des hirsutismes. 
En effet, si la $\Delta 4$-androstène-dione est principalement sécrétée par l'ovaire, le sulfate de déhydro-épiandrostérone (DHEA-S) est à 90\% d'origine corticosurrénalienne.

\subsection{LE DOSAGE DES GONADOTROPHINES}

Ce dosage par méthode radioimmunologique présente de même un certain intérêt.

Pendant l'enfance, le taux des gonadotrophines est faible ; il s'élève avant la puberté pour atteindre progressivement les taux de la femme fonctionnelle (voir cycle ovarien). A la ménopause, les taux augmentent de façon importante pour rester en plateau aux alentours de $100 \mathrm{mUI} / \mathrm{ml}$. En cas de castration, d'effondrement fonctionnel de l'ovaire, les taux de FSH-LH sont également élevés et participent ainsi au bilan étiologique des aménorrhées primaires ou secondaires.

Des tests dynamiques peuvent parfois être pratiqués :

- Le test au citrate de clomifène (Clomid®) (fig. 12.15)

Le citrate de clomifène est un inducteur de l'ovulation. Il agit par inhibition compétitive du rétro-contrôle des œstrogènes au niveau de l'hypothalamus.
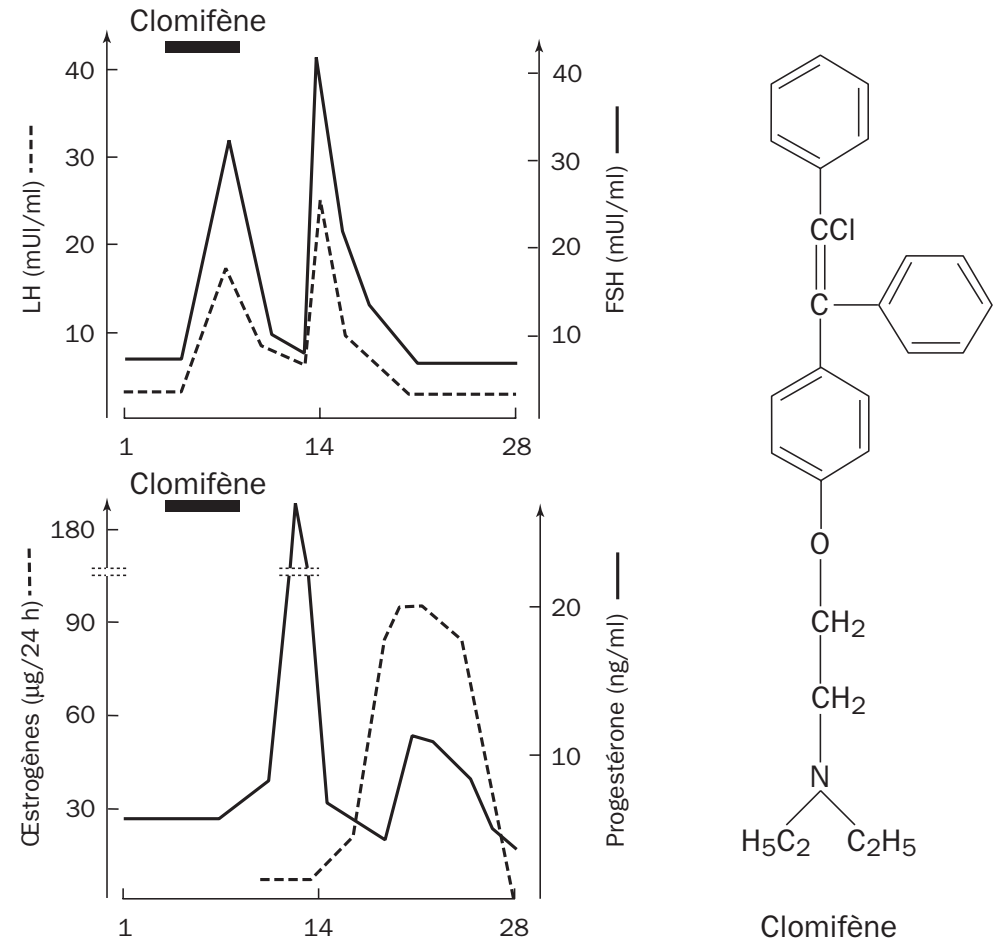

Figure 12.15 - Action du clomifène sur la sécrétion des hormones sexuelles chez la femme (d'après Tourniaire et Fèvre, 1979)

Lorsque le taux des gonadotrophines est bas, qu'il importe d'explorer l'étage en cause dans le déterminisme de l'aménorrhée, on pratique le test du clomifène qui 
vérifie l'intégrité de l'étage suprahypophysaire de l'axe hypothalamo-hypophysoovarien.

On administre le clomifène à raison de $100 \mathrm{mg} /$ jour pendant 5 jours consécutifs, en contrôlant les taux plasmatiques de FSH-LH pendant le cycle qui suit. Une réponse hormonale se traduit par une élévation des gonadotrophines dans la semaine qui suit l'arrêt du traitement. C'est le pic clomifénique équivalent de la décharge ovulante, témoin de l'intégrité fonctionnelle hypothalamique.

- Le test au LH-RH (Stimu-LH®)

Ce test peut également être utilisé : l'injection intraveineuse de 25 à $100 \mathrm{mg}$ de LH-RH agit directement sur l'hypophyse et engendre une libération précoce de FSH et de LH dans les $2 \mathrm{~h}$. Une réponse positive reflète le bon état fonctionnel de l'hypophyse.

Le déterminisme de l'atrésie folliculaire, qui aboutit à la sélection d'un lot limité de follicules ovulatoires (et en général un seul hors de chaque cycle ovarien), est complexe. Il semble que n'importe quel follicule qui entre en développement terminal hors d'une vague folliculaire ait les potentialités de se développer jusqu'au stade préovulatoire. Chaque follicule est caractérisé par un équilibre local entre des facteurs paracrines stimulants (œstradiol, IGF, activine...) et inhibiteurs (androgènes, IGFBP ou IGF binding proteins, follistatine...). Seul le follicule le mieux adapté continuerait son développement (évolution opportuniste plutôt que prédéterministe). Les autres, sous l'effet d'une augmentation de la synthèse de facteurs inhibiteurs et la perte de synthèse de facteurs stimulants, rentreraient en atrésie : activation de Fas et du récepteur du TNF $\alpha$ (tumor necrosing factor), déséquilibre en faveur des facteurs proapoptotiques (Bcl-2), activation de p53 et des caspases (Monniaux et coll., 1999). 
